Article

\title{
Research on the Pricing Model of the Dual-Channel Reverse Supply Chain Considering Logistics Costs and Consumers' Awareness of Sustainability Based on Regional Differences
}

\author{
Juhong Chen, Di Wu * (1) and Peng Li \\ School of economics and management, Xi'an University of Technology, Xi'an 710048, China; \\ chenjh@xaut.edu.cn (J.C.); lipenggn@xaut.edu.cn (P.L.) \\ * Correspondence: wdfrancis@stu.xaut.edu.cn; Tel.: +86-6266-0206
}

Received: 17 May 2018; Accepted: 15 June 2018; Published: 28 June 2018

check for updates

\begin{abstract}
With the prevalence of Internet technology, many recycling centers have developed a dual-channel reverse supply chain by introducing online recycling channels on the basis of offline third-party recyclers (TPR). In addition, great imbalanced development has been observed in different regions in China, as supported by the literature review. It is necessary to help companies in the supply chain to adjust their pricing strategies according to regional differences. This paper is aimed at answering the following two questions: (1) After introducing online channels, what strategies should the recycling center adopt to adjust online recycling prices and to readjust the transfer price of offline channels? (2) How do recycling centers and TPR in city A \& B modify their pricing strategies in accordance with logistics costs or consumers' awareness of sustainability changes in city B? To solve the above questions, models were made to study the pricing strategies of recycling centers and the TPR based on the Stackelberg game in a dual-channel reverse supply chain in two cities. The results indicate that recycling centers will benefit from the increase in consumers' awareness of sustainability and the reduction in logistics costs of the online channel in city B; this is in contrast to the TPR in this city. We also find that the revenue of the TPR in city A will be affected when the above two factors in city $B$ change. Its increase or decrease depends on the selection of pricing strategy by the recycling center.
\end{abstract}

Keywords: dual-channel reverse supply chain; regional differences; pricing models; awareness of sustainability; Internet + recycling

\section{Introduction}

With the rapid development of science and technology, the speed of product updates has increased. In this context, the emissions of waste are gradually increasing, which seriously aggravates environmental problems such as resource shortage and environmental pollution. In fact, many countries have enacted relevant laws and policies to require enterprises to take responsibility for the proper handling of waste products to strengthen sustainable development. For example, as early as 1984, the OECD (Organization for Economic Co-operation and Development) developed EPR (extended producer responsibility) to ensure that products were guaranteed throughout their life cycle, particularly in the abandonment phase. This policy has profoundly affected many countries such as the U.S., South Korea, and China, etc. For example, the South Korean government requires battery manufacturers to develop target recycling of used batteries. If the target cannot be achieved, the battery manufacturer will be fined [1].At the same time, the Chinese government has also enacted laws requiring producers to pay a part of the recycling fee [2]. In addition, many European countries 
have also signed the directives of WEEE (Waste of Electric and Electronic Equipment) (2002/96/EC) and RoHS (restriction of hazardous substances) in 2003 and 2006, in order to make electrical and electronic products that are conducive to environmental protection restrictions and norms at both the production and the end-of-life stages. However, as the saying goes: one man's trash is another man's treasure [3]. That is, if enterprises can effectively recover and remanufacture the waste, they can not only solve the above environmental problems, but can also help obtain huge profits, enhance their competitiveness, and improve their social influence [4,5]. According to the White paper on the 2016 WEEE of the recycling industry in China [6], 30.6 million TV sets, 21.85 million microcomputers, and 182.91 million mobile phones were scrapped in China alone in 2016, meaning that the recycling industry has an amazing market.

In recent years, based on the development of Internet technology, the Chinese government has developed a new model of "Internet + recycling" on the basis of the traditional recycling mode. The combination of "Internet + recycling" and the traditional recycling mode can be understood as a kind of dual-channel reverse supply chain. In this model, there are not only the traditional offline recycling channels, that is, with third-party recyclers (TPR), the consumers can deliver the waste products to the TPR and recycling centers, but also the online recycling model where consumers can use websites and APPs to deliver the waste products to the recycling centers directly.

As for the online channels, as long as the consumers input the brand, the model number and the damage and other information of the scrap product on the Internet site, they can obtain quotes from the recycling center. If the two sides agree on the price, the consumer can express the waste product to the recycling center, or the logistics company under the recycling center can go to the consumer's home to pick it up. The online channel will not only improve the responsiveness and efficiency of recycling, but also enhance the quality and conversion rate of recycling to reduce the pollution emissions to the environment through direct contact between the consumers and a professional recycling center [7]. On the other hand, consumer's awareness of sustainability is defined as consumer who constantly buys eco-friendly products and is actively concerned with sustainable issues and solutions to them [8]. Moreover, some scholars pointed out that consumers' awareness of sustainability also involves the choice of recycling behavior [9,10]. However, according to the report titled Report on Consumer Awareness and Behavior Change in Sustainable Consumption, there are obvious differences in sustainability awareness among the 10 surveyed Chinese cities. It is this phenomenon that has led to the different preferences of consumers in different regions when they choose online or offline channels, especially in China where regional development is imbalanced [11]. This requires recycling centers and TPR to enact different recycling prices in different areas to maximize their own revenue. However, till now, research on "Internet + recycling" in the academic world is still in its initial stage. Most research is in the form of qualitative studies focusing on its connotations, characteristics and mechanism [7,12]. There are a few quantitative studies on the dual-channel reverse supply chain, but the effect of regional differences on recycling companies are ignored [13-15]. Therefore, it is of great significance to consider regional differences in the pricing decisions of the dual-channel reverse supply chain.

The aim of this paper is to propose pricing strategies and maximize the benefits of recycling centers and the TPR. The first priority of the companies is to consider how much recycling can be affected by the income distribution, a consumer's income, the population and their preferences as well as the price. It is difficult to take all of these factors into consideration. Based on previous scholars' research on demand for the dual-channel reverse supply chain [16,17], this paper determines the amount of recycling in different channels by using the basic amount of consumers' waste products, the awareness of sustainability and the sensitivity between channels. On this basis, we can obtain the revenue function of recycling centers and the TPR, which includes the amount, price and cost of recycling. The focus of this paper is the following two issues:

(1) What strategies should recycling centers adopt to price online recycling and to readjust the offline transfer price after introducing online channels? 
(2) How do recycling centers and the TPR in different regions modify their pricing strategies in accordance with logistics costs or consumers' awareness of sustainability changes?

In order to solve the aforementioned two problems, we first discuss the optimal pricing decisions of the recycling center and TPR before introducing online channels. Secondly, we established three types of pricing strategy for the recycling center after the introduction of the online channel. To set up and compare the models based on the Stackelberg game, on the one hand, we provide the recycling center with the chance to make the optimal decision in different circumstances. On the other hand, we take the perspective of the TPR in different cities to optimize their pricing and revenue decision. Finally, the conclusion of the model is verified by an example analysis. This paper sheds light on the introduction of online recycling channels, considering the logistics costs and consumers' awareness of sustainability in the study of the reverse supply chain. By considering regional differences, we extend the options of the price models of both recycling centers and the TPR. The findings of this paper may provide a reference for the pricing decisions and further development of different types of recycling enterprises, and give support to consumers who seek to strengthen the recycling of waste products by means of environmental protection and promoting the sustainable development of resources.

Therefore, the main contribution of this paper is to increase the revenue of companies in the dual-channel reverse supply chain and reduce system conflicts (such as opportunism and fraud $[18,19]$ ) by applying different pricing strategies. This study took into account various factors such as the sustainability awareness of consumers, the logistical costs of online channels, the sensitivity of demand to prices, the interaction between online and offline channels, and other factors in the process of building the Stackelberg game model. By developing three different pricing strategies, the study found that consumers' awareness of sustainability and the cost of online channels had a significant impact on the pricing and benefits of TPR and recycling centers. In addition, according to the different stages of online channel introduction, this study gave management significance to different supply chain members. According to the specific operation of the pricing strategy, recycling centers can successfully introduce online channels, and make the best choice for a steady increase in profits when faced with regional differences. At the same time, from the perspective of the TPR, they can make timely and reasonable pricing decisions to reduce losses and increase profits indirectly by observing changes in the decisions of other recycling enterprises and regional differences.

The rest of this paper is set out as follows. Section 2 summarizes the related literature. Section 3 formulates and describes the problems studied. Section 4 establishes a mathematical model. In Section 5, the examples of the model are tested and validated. Finally, the conclusions and future research are given in Section 6.

\section{Literature Review}

This study was to collect papers from the three aspects of reverse supply chain, dual-channel reverse supply chain, and dual-channel forward supply chain, and only focused on the articles closely related to this study. When applicable, we collected and commented on the literature on the impact of regional differences on supply chains, since they hold a central role in our research. Other studies involving the closed loop supply chain (CLSC) were also reviewed as it shares interlinked areas with the reverse supply chain. To take all key factors from these studies into consideration, we compare the literatures in Table 1. In the reverse supply chain, the way that consumers recycle used products to recycling centers or manufacturers is further decomposed [20]. The reverse supply chain has been studied in different fields such as revenue-sharing contracts [21], quality and cost of information [22], designing and planning [23], and coordination of the supply chain [24]. In addition, especially for the pricing of waste products, many scholars have studied it. 
Table 1. Literature on pricing models.

\begin{tabular}{|c|c|c|c|c|c|c|c|c|}
\hline & $\begin{array}{l}\text { Supply Chain } \\
\text { Members }\end{array}$ & Game Type & The Leader & Decision Variables & $\begin{array}{c}\text { Influencing Factors } \\
\text { of Pricing }\end{array}$ & Dual-Channel & $\begin{array}{l}\text { Online Recycle } \\
\text { Channel }\end{array}$ & $\begin{array}{l}\text { Considering Regiona } \\
\text { Differences }\end{array}$ \\
\hline Gu 25 & $\begin{array}{l}\text { Manufacturer and } \\
\text { retailer }\end{array}$ & $\begin{array}{l}\text { Stackelberg } \\
\text { game; Nash } \\
\text { equilibrium }\end{array}$ & Manufacturer & Price: transfer, waste & $\begin{array}{l}\text { Cost: manufacture, } \\
\text { operations }\end{array}$ & No & No & No \\
\hline Wang 26 & $\begin{array}{c}\text { Manufacturer and } \\
\text { retailer }\end{array}$ & $\begin{array}{l}\text { Stackelberg } \\
\text { game }\end{array}$ & Manufacturer & $\begin{array}{l}\text { Price: wholesale, retail, } \\
\text { transfer, waste }\end{array}$ & $\begin{array}{l}\text { Cost: manufacture, } \\
\text { operations }\end{array}$ & No & No & No \\
\hline Savaskan 27 & $\begin{array}{l}\text { Manufacturer, retailer } \\
\text { and third-party } \\
\text { recyclers (TPR) }\end{array}$ & $\begin{array}{l}\text { Stackelberg } \\
\text { game }\end{array}$ & Manufacturer & $\begin{array}{l}\text { Price: wholesale, retail, } \\
\text { transfer, waste }\end{array}$ & Cost and return rate & No & No & No \\
\hline Huang 28 & $\begin{array}{l}\text { Manufacturer, retailer } \\
\text { and TPR }\end{array}$ & $\begin{array}{l}\text { Stackelberg } \\
\text { game }\end{array}$ & Manufacturer & $\begin{array}{l}\text { Price: wholesale, retail, } \\
\text { transfer, waste }\end{array}$ & $\begin{array}{l}\text { Cost and competing } \\
\text { coefficient }\end{array}$ & Yes & No & No \\
\hline Hong 29 & $\begin{array}{l}\text { Manufacturer, retailer } \\
\text { and TPR }\end{array}$ & $\begin{array}{l}\text { Stackelberg } \\
\text { game }\end{array}$ & Manufacturer & $\begin{array}{l}\text { Price: wholesale, retail, } \\
\text { transfer, waste }\end{array}$ & Cost and return rate & Yes & No & No \\
\hline $\operatorname{Li} 13$ & $\begin{array}{l}\text { Recycling center, TPR } \\
\text { and TPR platform }\end{array}$ & $\begin{array}{l}\text { Stackelberg } \\
\text { game }\end{array}$ & Recycling center & $\begin{array}{l}\text { Price: waste, transfer, } \\
\text { online waste }\end{array}$ & $\begin{array}{l}\text { Cost and online } \\
\text { channel preferences }\end{array}$ & Yes & Yes & No \\
\hline Feng 14 & $\begin{array}{l}\text { Recycling center } \\
\text { and TPR }\end{array}$ & $\begin{array}{l}\text { Stackelberg } \\
\text { game }\end{array}$ & Recycling center & $\begin{array}{l}\text { Price: waste, transfer, } \\
\text { online waste }\end{array}$ & $\begin{array}{l}\text { Cost and online } \\
\text { channel preferences }\end{array}$ & Yes & Yes & No \\
\hline Giri 15 & $\begin{array}{l}\text { Manufacturer, retailer, } \\
\text { recycling center } \\
\text { and TPR }\end{array}$ & $\begin{array}{l}\text { Stackelberg } \\
\text { game }\end{array}$ & $\begin{array}{l}\text { Consider all } \\
\text { situations }\end{array}$ & $\begin{array}{l}\text { Price: wholesale, retail, } \\
\text { online retail, waste, } \\
\text { transfer, online waste }\end{array}$ & Cost and return rate & Yes & Yes & No \\
\hline Chiang 40 & $\begin{array}{l}\text { Manufacturer } \\
\text { and retailer }\end{array}$ & $\begin{array}{l}\text { Stackelberg } \\
\text { game }\end{array}$ & Manufacturer & $\begin{array}{l}\text { Price: wholesale, retail, } \\
\text { online }\end{array}$ & $\begin{array}{l}\text { Cost and acceptance } \\
\text { of online channel }\end{array}$ & Yes & No & No \\
\hline Huang 41 & $\begin{array}{l}\text { Duopoly model of } \\
\text { two manufacturers }\end{array}$ & $\begin{array}{l}\text { Nash } \\
\text { equilibrium }\end{array}$ & / & Price: online, offline & $\begin{array}{c}\text { Costs and } \\
\text { substitutability } \\
\text { factors }\end{array}$ & Yes & No & No \\
\hline Sheng 36 & $\begin{array}{l}\text { Manufacturer } \\
\text { and retailer }\end{array}$ & $\begin{array}{l}\text { Stackelberg } \\
\text { game }\end{array}$ & Manufacturer & $\begin{array}{c}\text { Price: wholesale, retail, } \\
\text { online }\end{array}$ & $\begin{array}{l}\text { Cost and acceptance } \\
\text { of online channel }\end{array}$ & Yes & No & Yes \\
\hline Xu 37 & $\begin{array}{l}\text { Manufacturer } \\
\text { and retailer }\end{array}$ & $\begin{array}{l}\text { Stackelberg } \\
\text { game }\end{array}$ & Manufacturer & $\begin{array}{c}\text { Price: wholesale, retail, } \\
\text { online }\end{array}$ & $\begin{array}{l}\text { Cost and acceptance } \\
\text { of online channel }\end{array}$ & Yes & No & Yes \\
\hline
\end{tabular}




\subsection{Reverse Supply Chain}

For the pricing problems of recycling in the reverse supply chain, most scholars study it through the comparison of the forward supply chain, from the perspective of enterprise game and supply chain coordination. $\mathrm{Gu}[25]$ pointed out that as the traditional pricing strategies of a forward supply chain are not all suitable for a reverse supply chain, and to solve this problem constructed the pricing model involving a single manufacturer and retailer by using the Stackelberg game and Nash equilibrium theory. Wang [26] extended Gu's research, and studied the pricing problem of reverse supply chains in centralized and decentralized modes. The above studies are promising attempts to introduce recycling pricing into the reverse supply chain. In addition, making the model based on centralized and decentralized decisions can further enhance the income of enterprises and promote coordination among channels. On the other hand, with the diversification of recycling channels, scholars have also focused on research from the perspective of recycling channel selection. Savaskan [27] constructed the pricing model of three models of manufacturer recycling, retailer recycling, and third-party recycling, and compared them to propose the optimal pricing strategy under different applicable conditions. Although this research focused on the advantages and disadvantages of different recycling channels, it failed to analyze the competition and interaction between channels when they co-exist. Therefore, based on the research of Savaskan, Huang [28] built a competitive hybrid recycling model for retailers and third-party recyclers, and compared the system benefits of the model with a single channel recycling model. He pointed out that when the channels of the reverse supply chain were competitive, the hybrid mode would be better than the single channel recycling model. However, Huang focused on only a single type of mixed channel, without considering other types of recycling channels and the competition and conflicts between them. In fact, in the supply chain, the intensification of conflicts among different channels and enterprises will lead to opportunistic behavior, deception or other incorrect decisions $[16,17]$. Furthermore, in order to mitigate the conflicts in the reverse supply chain, Hong [29] proposed a recycling model of three kinds of mixing channels, manufacturer and third-party recyclers, retailers and third-party recyclers, manufacturers and retailers and pointed out that the recycling efficiency of the third mode was the highest through numerical simulation. From the comparison of the literature above, as presented in Table 1, we find that in the research on the pricing problem in the reverse supply chain, scholars mainly based their studies on the Stackelberg game and on the hypothesis that the manufacturers are in the dominant position. In addition, the choice of recycling channels and the conflict between channels have always attracted the attention of scholars. All of these factors provide useful information for this paper in its research questions and methodology. However, although the above research works all made sense for studying the pricing problem in the reverse supply chain from multiple perspectives, they all ignored the influence of the Internet. In fact, the prevalence of the Internet and the emergence of online channels will fundamentally complicate the structure of the reverse supply chain and, accordingly, promote the transformation of the decision-making process of recycling companies.

\subsection{Dual-Channel Reverse Supply Chain}

With the development of the Internet, the dual-channel reverse supply chain has developed rapidly and made great achievements in China. According to the statistics for China's largest online recycling company Loving Recycling, it recycled more than 11 million WEEEs in 2017. This recycling amount is 2.2 times that of 2016 [30]. In addition, to provide the foundation for promoting the development of "Internet + recycling", the Chinese government has also issued a series of policies, for example, the 2015 Circular Economy Promotion Plan [31] and Action Plan of Three-year "Internet +" Green Ecology [32]. However, research on the dual channel reverse supply chain is still in its infancy. As early as 2010, Zhang [33] used the automotive industry as an example and pointed out that the application of the Internet of Things and radio-frequency identification (RFID) technology in the products' scrap phase could effectively collect and analyze the information needed to be recycled, and enhance the management of the product life cycle. Although this study has been widely recognized 
and quoted in academic circles, it is not deep enough in discussing the operations of the recycling enterprise. Therefore, in 2016, Li and Feng [13] were the first to study the sustainable pricing problem of the dual-channel reverse supply chain. By introducing consumer preferences for the network recycling channel, they compared the traditional offline recycling model and different types of dual-channel recycling model, and through numerical simulation, pointed out the existence of a Pareto interval of consumer preference, which makes the benefits from the dual-channel model always better than from the traditional one. This article conducted a more in-depth exploration of the model construction and operation method of the dual-channel reverse supply chain. What is more, as the first attempt to solve the pricing problem of the field, this study has provided a solid foundation for further quantitative research. After solving the problem of recycling pricing, it is important to promote coordination among channels. Therefore, they expanded the research [14] in an article published in the European Journal of Operational Research in 2017 to build pricing models for both centralized and decentralized decision-making, and develop corresponding revenue-sharing contracts. In the end, through numerical analysis, they pointed out that the consumers' preference for online channels would affect the acceptance of contracts by different recyclers. The findings of this article not only promote the coordination of different recycling channels, but also help different recycling enterprises to achieve a win-win result. All of the above studies have put recycling centers in the dominant position. However, in reality, a TPR can also be in control, for example IBM's global asset recovery services and AER worldwide [34,35]. In addition, Giri [15] conducted research on the coordination of the supply chain when the different members occupied the dominant position in the online recycling of the dual-channel closed loop supply chain, and through numerical simulation compared the profits of the system when the manufacturers, retailers, and the third-party recyclers occupied the dominant position, respectively. The final results showed that the whole system had the highest revenue when the retailer dominated. In combination with the data in Table 1, the research on the dual channel reverse supply chain mainly puts the recycling center in the dominant position. The researchers also paid attention to the cost and consumer factors, using the Stackelberg game to solve their pricing models. Although the above scholars considered factors such as consumer behavior, enterprise dominance, and inter-channel conflict in the research of the dual-channel reverse supply chain, they all neglected the great differences in different regions, especially in China, whose development is very uneven [11]. The sustainable awareness of consumers, the cost of online channels and the conflict between channels in different regions are completely different. However, dual-channel forward supply chains have been studied in detail [36,37]. In addition, we must note that research in this field is still at an early stage. Given the fact that research on the dual-channel forward supply chain has been developing for many years in both reality and theory, we can borrow many of its elements as references for this paper, such as research background, design and method.

\subsection{Dual-Channel Forward Supply Chain}

In the forward supply chain, many manufacturers have developed a dual-channel based on online and offline channels. There is already in-depth research on the dual-channel supply chain in the academic world. In the dual-channel supply chain, the introduction of the online channel can seize customer resources of the traditional offline channel; on the other hand, it can reduce the double marginal effect to improve the performance of the whole supply chain [21,38]. Therefore, as for the traditional offline channel, the online channel is both an opportunity and challenge [39]. For the problem of the pricing strategy of the dual-channel, scholars have studied it mainly from the points of view of competition and conflict of the online and offline channels, market potential, channel substitutability and consumer perception, etc. Chiang [40] pointed out that the introduction of online channels could not only improve the competitiveness of the manufacturers, but was harmless to retailers as it could reduce wholesale prices. From this, we can see that the introduction of online channels is not always a threat to retailers. Manufacturers can achieve a balanced game among enterprises through reasonable pricing strategies, and at the same time enhance their own and retailers' 
benefits. The deficiency of the research is that the models proposed are relatively simple; they cannot give different choices to manufacturers in the face of changing situations. To solve this problem, Huang [41] constructed the demand model and four pricing strategies according to the channel substitution degree and the overall market potential, and analyzed the four strategies through a numerical simulation. The main contribution of this paper is to formulate different pricing and revenue strategies for enterprises that plan to introduce online channels according to different situations of offline enterprises. The limitation of this paper is that its study on the demand function is only a simple consideration of the exchange between the channels, without considering the changes brought by the consumer's behavior. In order to solve this deficiency, Hua [42] pointed out that the online recycling channel had an advantage in the quality of service when compared to the offline recycling channel, and that the consumer's acceptance of online channels had a great impact on pricing. The above research on the dual-channel supply chain provides important references to formulate the question and design of the model in this paper. However, it has neglected the problem of unbalanced development worldwide, especially in China, and its possible impact on business decision making [43]. Therefore, some scholars have pointed out that due to the imbalance of regional development, the differences between different regions has an important impact on the decision-making of the dual-channel supply chain [36]. Sheng and $\mathrm{Xu}$ [36] built a dual-channel supply chain pricing model for manufacturers of different regions, and pointed out that the differential pricing strategy could improve the overall income of the dual-channel supply chain. It is different from optimizing the profit from the manufacturer's perspective, after that, they extended the research [37] to the model of a retailer's profit, and built three pricing strategies of invariable wholesale price, the same wholesale price, and the maximum of overall profit, and compared them through numerical simulation. The above studies provided a theoretical basis for the impacts of regional differences on the decision making of enterprises in the dual-channel supply chain. According to the data in Table 1, we can see that the research on the pricing strategy of enterprises still used the Stackelberg game which puts the manufacturer in the dominant position, and combined the factors of consumer preference, regional differences and channel conflicts to optimize the pricing decision and income of the enterprises. Furthermore, there are many similarities between the forward and reverse supply chains, such as the dominance of manufacturers or recycling centers and their efforts to introduce online channels, and the direct contact of retailers or the TPR with the consumers. Therefore, due to the characteristics of sustainable development, resource conservation and environmental protection in the recycling industry, the consideration of regional differences in the dual-channel reverse supply chain will bring new theoretical and practical significance to this field.

\subsection{Discussion}

To sum up, scholars have studied in depth the pricing of the reverse supply chain and dual-channel forward supply chain from the perspective of method selection, channel coordination, consumer behavior and regional differences. In addition, they provide references for our new insights and construction on the research on the dual-channel reverse supply chain that both considers online channel and regional differences. Moreover, we find that almost all the research adopts the Stackelberg game to solve the pricing problem. This is because game theory can help them to take their prediction behavior and actual behavior into consideration according to the objectives, interests and possible action plans of different individuals in the supply chain. Through comprehensive consideration of the parties' most reasonable choice of action to the game, game theory can obtain their optimal strategies [27,40]. All of these have provided an important reference for our research on the dual-channel reverse supply chain. Although there have been some studies on the dual-channel reverse supply chain, our research was different. First, our research goal was the pricing problems of the dual-channel reverse supply chain. In its pricing model, there are both online and offline recycling channels; second, in order to describe the impact of regional differences on pricing strategy, we took the logistical costs and consumers' awareness of the online channel into consideration. We must 
understand that in the past, research on consumer awareness in the sustainable supply chain was qualitative rather than quantitative [44-46]. Finally, through the solved model, we drew a number of conclusions, and used the numerical example to verify them and to propose some suggestions for the node enterprises in the dual-channel reverse supply chain.

\section{Model Assumptions and Notations}

The goal of this paper was to deal with the pricing problem created by the regional differences for node enterprises in the supply chain in the dual-channel reverse supply chain. To this end, we built a dual-channel reverse supply chain model with the consideration of two different cities A and B, where the recycling center can use traditional offline channels and online channels to recycle the waste products from consumers in different regions. Under traditional offline recycling, consumers will transfer the waste products to the local third-party recyclers at a certain price, and the third-party recyclers will carry out the preliminary classification and treatment of the waste products and then transfer them to the recycling centers. In this model, the recycling center and the third-party recyclers follow the Stackelberg game. In the use of online recycling channels, consumers will release the information of waste products through mobile phones or personal computers to the online platform established by the recycling center, and then directly hand over the waste products to the recycling center through express or door-to-door recycling. There are two main types of regional differences between the two cities A and B, namely, the consumer's awareness of sustainability and the logistical costs of the electronic channels.

Based on Savaskan's research [27], we first made the following assumptions about the cost of running the recycling enterprises, the regional differences between different cities, and the framework for making decisions:

Assumption 1. All the waste products have the same recycling conversion rate. There are many household appliances that can be recycled by online channels. However, for simplicity, according to the research in $[13,14,25,26]$, in this study we only considered a batch of electronic products of the same type, brand, and degree of loss that have been sorted by recycling centers.

Assumption 2. The vast majority of recycling centers we considered were all individual companies. For example, as the largest "Internet + recycling" companies in China at present, Love Recycling, Recycling Treasure, and Recycling Brother are all individual companies. Furthermore, these companies all operate with the goal of maximizing their profits. Therefore, all the decision goals of all supply-chain members are to maximize their own benefits. In addition, the information obtained by the parties in the supply chain was symmetrical to avoid problems such as inefficiencies and risk sharing of the supply chain due to asymmetric information.

Assumption 3. Since in the model we are considering the market position of recycling centers and TPR is not equal, leading to the result that the asymmetry of market position has aroused the asymmetry of decision sequence. So, we did not consider the Cournot model and Bertrand model, but considered the Stackelberg game to solve the problem in this paper.

Assumption 4. The recycling center is the leader in the Stackelberg game with TPR. We made this assumption as the result of a combination of various factors. First, recycling centers have absolute economic strength compared to TPR. For example, a recycling center called Loving Recycling has gained more than $\$ 130$ million in financing [30]. However, TPRs are mostly small-scale individual recyclers. Second, the recycling center can obtain the support of the government, which allows it to obtain the government's subsidies and legitimacy. On the other hand, although the number of TPRs is huge, they are actually not recognized by the government. Finally, TPRs do not have the ability to deal with waste after recycling it. They can only transfer waste to recycling centers for profit. Therefore, they have no say in bargaining with recycling centers. In summary, recycling centers are the leaders in this case. Therefore, in the game of the two parties, the recycling center can make the most favorable decision by observing the reaction of the TPR. 
Assumption 5. We set the sustainable logistics cost of the online recycling channel to $c_{i}\left(c_{i}>0\right)$ and ignored the logistics cost of the offline channel. For most types of waste products, especially the electrical waste and electronic products, as the traditional offline recycling mode usually obtains bulk transportation, the logistics cost shared by every waste product is very low, which can be ignored. However, as mentioned in $[13,15]$, in the online recycling channels the waste products are delivered to the recycling center in a sustainable way by express delivery or door-to-door delivery singly, so the logistics cost is much higher than that of offline.

Assumption 6. Compared to offline channels, online channels take advantage of higher recycling prices, convenience services, and formal processes. Therefore, in the actual situation, many factors can improve the sustainable awareness of online recycling channels by consumers. In this article, we assumed that the index of a consumer's sustainable awareness was $\theta_{i}(i=1,2)$, the sustainable logistics cost of the electronic channels was $c_{i}(i=1,2)$, the recycling price of the online channel was $p_{e}$, and the recycling price of the offline channel was $p_{i}(i=1,2)$.

Assumption 7. In this paper, we assumed that the recycling quantity and price of waste products were linearly distributed, that is, in the recycling model with only traditional channels, the relationship between the amount of recycling $d_{r i}(i=1,2)$ and the price was: $d_{r i}=a_{i}+\beta_{i} p_{i}$. In the dual-channel mode with both online and offline recycling channels, the recycling amount is affected by the recycling price, awareness and logistics costs of sustainability. In another way, the amount of offline recycling channel was $d_{r i}=\left(1-\theta_{i}\right) a_{i}+\beta_{i} p_{i}-\gamma_{i} p_{e}$, and the amount of the online recycling channel was $d_{e i}=\theta_{i} a_{i}+\beta_{i} p_{e}-\gamma_{i} p_{i}$.

The notation in Table 2 will be used in the formulation, where $i=1$ represents city A and $i=2$ represents city $B$.

Table 2. Notation.

\begin{tabular}{|c|c|}
\hline Symbol & Definition \\
\hline$d_{r i}$ & The recycling amount of waste products in offline channel $(i=1,2)$. \\
\hline$d_{e i}$ & The recycling amount of waste products in online channel $(i=1,2)$. \\
\hline$\theta_{i}$ & $\begin{array}{l}\text { The index of consumers' sustainable awareness. It means as } \theta_{i} \text { increases, the number of } \\
\text { consumers who are willing to choose online channels in the region will also increase. } \\
\left(\theta_{i}>0, i=1,2\right) \text {. }\end{array}$ \\
\hline$c_{i}$ & The sustainable logistics cost of electronic channels $(i=1,2)$. \\
\hline$p_{0}$ & $\begin{array}{l}\text { The benefits obtained by the recycling center through the removal, decomposition and } \\
\text { remanufacturing of waste products in units. }\end{array}$ \\
\hline$p_{i}$ & $\begin{array}{l}\text { The unit price at which TPR recycles waste products from consumers through offline } \\
\text { channel }(i=1,2) \text {. }\end{array}$ \\
\hline$p_{e}$ & $\begin{array}{l}\text { The unit price at which the recycling center recycles waste products from consumers } \\
\text { through online channel. }\end{array}$ \\
\hline$w_{i}$ & The transfer price at which TPR recycles waste products to recycling center $(i=1,2)$. \\
\hline$a_{i}$ & Basic quantity of waste products in the hands of consumers $\left(a_{i}>0, i=1,2\right)$. \\
\hline$\beta_{i}$ & The price of sensitivity of consumers in region $i\left(\beta_{i}>0, i=1,2\right)$. \\
\hline$\gamma_{i}$ & $\begin{array}{l}\text { The diffusion rate of consumers in region } i \text {, describing the extent of diffusion of demand } \\
\text { between the two channels due to price changing }\left(\beta_{i}>\gamma_{i}>0, i=1,2\right) \text {. }\end{array}$ \\
\hline$\prod_{m}$ & The benefits of recycling center. \\
\hline$\prod_{i}$ & The benefits of TPR $(i=1,2)$. \\
\hline
\end{tabular}

\section{Model Formulation and Solution}

We analyzed the traditional model and the dual-channel model separately in this section. For the Stackelberg game between the recycling center and TPR, we first analyzed the equilibrium model and the optimal pricing strategy that could be achieved after the game under the traditional mode 
in Section 4.1, when the online recycling channel was not introduced and the recycling center set the unified pricing strategy and differential pricing strategy. With the development of the Internet and the promotion of government policies, and the introduction of online recycling channels into the reverse supply chain, we analyzed the reverse supply chain with both online and offline recycling channels. In view of the conflict between the recycling center and TPR, and the TPRs of different areas, these recycling enterprises can formulate the optimal pricing strategy. In this paper, the build sequence of the paper structure is gradually progressive, and the design of the strategy is inseparable from the previous conclusions. For example, the design of $w$ in Section 4.2.1 uses the conclusion of $w$ in Section 4.1.2.

\subsection{Traditional Models}

As in Figure 1, in the traditional mode, TPRs of different cities recycle the WEEE from consumers at the unit price of $p_{i}$. Then, the TPRs transfer the WEEE to the recycling center at the unit price of $w_{i}$. We used the Stackelberg game to analyze the strategies of TPR and recycling center. Since the recycling center is the leader, the recycling center first develops a general strategy (unify pricing or differential pricing), then the TPRs make specific pricing decisions. After observing the TPR's pricing decision, the recycling center makes the most favorable pricing decision based on the TPR's decision. Finally, the recycling center will completely decompose and disassemble the WEEE, and then reproduce or resell the spare parts and raw materials and obtain the unit income of $p_{0}$.

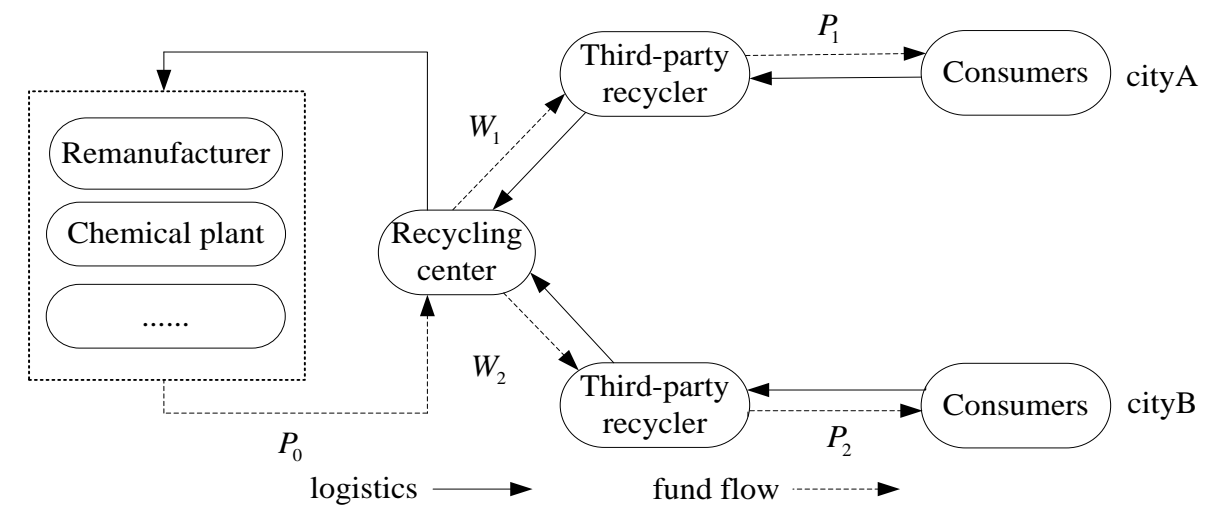

Figure 1. Depiction of the reverse supply chain in two cities.

\subsubsection{Unify Pricing}

We first considered that when the recycling center is the absolute leader in the supply chain, it uses a unified price $w$ to recycle waste products aimed at the TPR in different regions to facilitate its own price management and marketing management. The TPRs of different regions set the recycling price $p_{i}$ based on the transfer price $w$ established by the recycling center, according to the actual situation of their cities. Using the Stackelberg game, this paper studied the pricing strategies of the recycling centers and different TPRs. According to backward induction, due to the dominant position of the recycling center, the maximum benefit and optimal pricing of the TPR should be analyzed first. The transfer price $w$ established by the recycling center was observed, and then the revenue function $\prod_{i}$ of TPRs in different regions can be represented as:

$$
\prod_{i}=\left(w-p_{i}\right) d_{r i}=-\beta_{i} p_{i}^{2}+\left(w \beta_{i}-\alpha_{i}\right) p_{i}+w \alpha_{i}
$$

Property 1. The objective function $\prod_{i}$ is always concave with $p_{i}$.

The proof of Property 1 and other properties are enclosed in Appendix A. 
Setting $p_{i}^{*}$ as the optimal recycling pricing of TPR, then when $\partial \prod_{i} / \partial p_{i}=0$ and $p_{i}{ }^{*}=\left(w \beta_{i}-\alpha_{i}\right) / 2 \beta_{i}$, $\prod_{i}$ is arriving at its maximum. As the leader of the Stackelberg game, the recycling center can optimize its own pricing strategies after observing two TPRs' pricing strategies in different regions to obtain the maximum benefit. The benefits of the recycling center can be expressed as:

$$
\prod_{m}=\sum_{i=1}^{2}\left(p_{0}-w\right) d_{r i}=\left(p_{0}-w\right) \sum_{i=1}^{2}\left(\alpha_{i}+\frac{w \beta_{i}-\alpha_{i}}{2}\right)
$$

Property 2. The objective function $\prod_{m}$ is always concave with $w$.

Setting $w^{*}$ as the optimal recycling price of the recycling center to TPRs of different regions, then we can get:

$$
\partial \prod_{m} / \partial w=0, w^{*}=\frac{p_{0}\left(\beta_{1}+\beta_{2}\right)-\left(\alpha_{1}+\alpha_{2}\right)}{2\left(\beta_{1}+\beta_{2}\right)} .
$$

Substituting $w^{*}$ into $p_{i}^{*}$ in Equations (1) and (2), then we can get the maximal profit of the recycling center:

$$
\underset{p_{i}^{*}, w^{*}}{\operatorname{Max}} \prod_{m}=\frac{\left[p_{0}\left(\beta_{1}+\beta_{2}\right)+\left(\alpha_{1}+\alpha_{2}\right)\right]^{2}}{8\left(\beta_{1}+\beta_{2}\right)}
$$

The optimal price $p_{i}^{*}$ is:

$$
p_{i}^{*}=\frac{w \beta_{i}-\alpha_{i}}{2 \beta_{i}}=\frac{p_{0} \beta_{i}-3 \alpha_{i}}{4 \beta_{i}}
$$

The maximal profit of TPR is:

$$
\underset{p_{i}, w^{*}}{\operatorname{Max}} \prod_{i}=\frac{\left[\left(\beta_{i} p_{0}+2 \alpha_{i}\right)\left(\beta_{1}+\beta_{2}\right)^{2}\right]^{2}+\beta_{i}\left(\alpha_{1}+\alpha_{2}\right)\left[\beta_{i}\left(\alpha_{1}+\alpha_{2}\right)-\left(2 \beta_{i} p_{0}-4 \alpha_{i}\right)\left(\beta_{1}+\beta_{2}\right)\right]}{16 \beta_{i}\left(\beta_{1}+\beta_{2}\right)^{2}}
$$

\subsubsection{Differential Pricing}

In order to maximize its own income, the recycling center will make a differentiated pricing strategy based on the consideration of the factors of the quantity of the WEEE, the recycling ability of the TPR, and the rest held by consumers in different regions. In this type of pricing model, the recycling center is still the dominant power in the supply chain when compared to the TPR. The revenue function of TPR can be expressed as:

$$
\prod_{i}=\left(w_{i}-p_{i}\right) d_{r i}=-\beta_{i} p_{i}{ }^{2}+\left(w_{i} \beta_{i}-\alpha_{i}\right) p_{i}+w_{i} \alpha_{i}
$$

Similar to the demonstration in Property 1 , we can also get the objective function $\prod_{i}$ is always concave with $p_{i}$. Setting $p_{i}{ }^{*}$ as the optimal price of TPR, it is solved that, $\prod_{i}$ arrives at its maximum when $p_{i}{ }^{*}=\left(w_{i} \beta_{i}-\alpha_{i}\right) / 2 \beta_{i}$. According to Stackelberg game theory, the recycling center makes decisions on the pricing strategy of TPRs in two different regions, and the proceeds can be expressed as:

$$
\prod_{m}=\sum_{i=1}^{2}\left(p_{0}-w_{i}\right)\left(\alpha_{i}+\beta_{i} p_{i}^{*}\right)
$$

Property 3. The objective function $\prod_{m}$ is always concave with $w_{i}$.

The proof of Property 3 is enclosed in the Appendix A. 
Setting $w_{i}^{*}$ as the optimal recycling price of the recycling center to TPRs of different regions, on the basis of $\partial \prod_{m} / \partial w_{i}=0$, then $w_{i}^{*}=\left(p_{0} \beta_{i}-\alpha_{i}\right) / 2 \beta_{i}$ is obtained. Substituting $w_{i}^{*}$ into $p_{i}^{*}$ in Equations (6) and (7), respectively, then we can get:

The maximal profit of recycling center is:

$$
\underset{p_{i}^{*}, w_{i}^{*}}{\operatorname{Max}} \prod_{m}=\sum_{i=1}^{2} \frac{\left(\alpha_{i}+p_{0} \beta_{i}\right)^{2}}{8 \beta_{i}}
$$

The optimal price $p_{i}^{*}$ is:

$$
p_{i}^{*}=\frac{w \beta_{i}-\alpha_{i}}{2 \beta_{i}}=\frac{p_{0} \beta_{i}-3 \alpha_{i}}{4 \beta_{i}}
$$

The maximal profit of TPR is:

$$
\underset{p_{i}, w_{i}^{*}}{\operatorname{Max}} \prod_{i}=\frac{\left(\beta_{i} p_{0}+\alpha_{i}\right)^{2}}{16 \beta_{i}}
$$

Property 4. As for the recycling centers, the benefits of differentiated pricing strategies for different regions are always higher than the unified pricing strategy.

Through the proof of Property 2, we can observe that the differentiated pricing strategy for different regions can help the recycling center to improve its own income. Compared with the unified pricing strategy, the differentiated strategy can excavate the characteristics and habits of consumers in different market segments, that is, relying on different consumer groups to establish a scientific and reasonable pricing system to promote overall competitiveness.

\subsection{Dual-Channel Model}

On the basis of the traditional recycling model, the online recycling channel is introduced as shown in Figure 2. By contrast with the traditional mode, under dual-channel recycling mode with the coexistence of online and offline channels the recycling center not only indirectly recycles the waste products through the TPR, but also uses the network channel to directly recycle the waste products from consumers at the price of $p_{e}$. Therefore, the relationships between the recycling center and TPR are not only upstream and downstream in the supply chain, but are also competitive. Compared with the TPR, the online channel of the recycling center is superior to the traditional offline channel in terms of recycling price, quality, efficiency, and environmental sustainability, and these advantages can also enhance the index of a consumer's sustainable awareness $\theta$ of the online channel due to the increase of urban residents' awareness of environmental protection. However, the introduction of online channels will also mean competition with the offline channels. If such competition is not properly guided, it may lead to vicious conflicts between the different channels, and damage the benefits of the whole supply chain system. Therefore, in order to reduce the conflict between the recycling center and TPR in the process of introducing the online channel, according to the actual situation of the supply chain this paper has formulated three kinds of pricing strategy for the recycling center. Furthermore, although online channels are superior to offline channels in terms of price, service, and environmental friendliness, many consumers are still unable to accept online channels because of traditional concepts. Many consumers may not know there is such an online recycling method. This is why in our strategies, some consumers will still choose offline channels despite the lower prices of the online channel. 


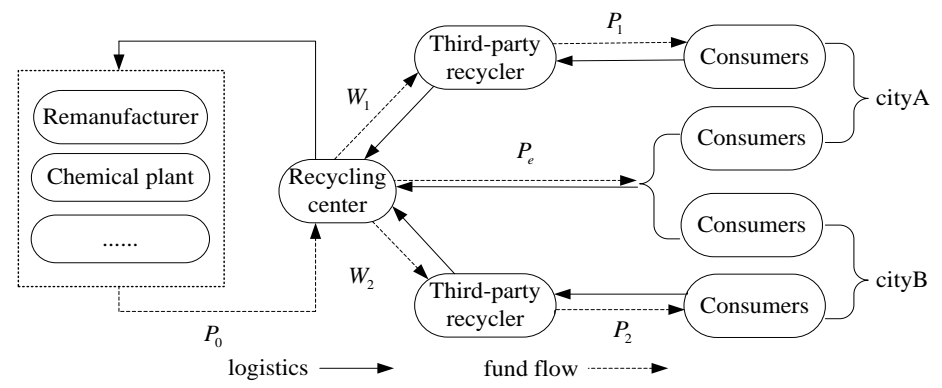

Figure 2. Depiction of the dual-channel reverse supply chain in two cities.

In this mode, we also used the Stackelberg game to analyze the strategies of the TPR and recycling center. Similar to the traditional model, the recycling center first develops a general strategy, then the TPR makes specific pricing decisions. After observing the TPR's pricing decision, the recycling center makes the most favorable pricing decision for the online and offline channels. Inspired by Cattani's handling of the conflict in the forward dual-channel supply chain [47], we built three pricing strategies for the recycling center to deal with the problem as the online channel is introduced: the recycling price is unchanged, unify all the prices, or maximize its own revenue.

\subsubsection{The Recycling Price is Unchanged}

In this situation, although the recycling center already has a certain size, the TPR still occupies a certain position during the exchange with the recycling center (the recycling center is still dominant). In other words, the recycling center still relies mainly on the offline channel for recycling within a short period of time after the introduction of online channels. Therefore, in order to reduce the opposition of the TPR, minimize the conflict, and maintain the stability of the supply chain, the recycling center should maintain the recycling price for the TPR. We used Catani's analogy of the "boiling frog" to describe this strategy [41]. When the frog is thrown into boiling water, the frog jumps out immediately. However, if you put the frog in warm water and simmer it, it cannot escape after realizing the danger. For recycling centers, it is necessary to consider the response of the TPR to avoid conflicts in the supply chain when introducing online channels. Therefore, the recycling center can first keep the transfer price for the TPR unchanged. After the online channel gains consumer recognition and has a certain market share, the recycling center can make further adjustments to pricing decisions. By then, the TPR could no longer react fiercely to online channels. In summary, in this chapter we assumed that the recycling center keeps $w_{i}^{*}=\left(p_{0} \beta_{i}-\alpha_{i}\right) / 2 \beta_{i}$ in Section 4.1.2 to recycle waste products from the TPR, so the revenue function of TPR in different regions can be written as:

$$
\prod_{i}=\left(w_{i}-p_{i}\right) d_{r i}=-\beta_{i} p_{i}^{2}+\left[w_{i} \beta_{i}-\left(1-\theta_{i}\right) \alpha_{i}+\gamma_{i} p_{e}\right] p_{i}+\left[w_{i}\left(1-\theta_{i}\right) \alpha_{i}-w_{i} \gamma_{i} p_{e}\right]
$$

Property 5. The objective function $\prod_{i}$ is always concave with $p_{i}$.

Setting $p_{i}^{*}$ as the optimal recycling price of the TPR, when $\partial \prod_{i} / \partial p_{i}=0$, and $p_{i}{ }^{*}=$ $\left[w_{i} \beta_{i}+\gamma_{i} p_{e}-\left(1-\theta_{i}\right) \alpha_{i}\right] / 2 \beta_{i}, \prod_{i}$ arrives at its maximum.

The revenue function of the recycling center is:

$$
\prod_{m}=\sum_{i=1}^{2}\left[\left(p_{0}-p_{e}-c_{i}\right) d_{e i}+\left(p_{0}-w_{i}\right) d_{r i}\right]
$$

Property 6. The objective function $\prod_{m}$ is always concave with $p_{e}$. 
Setting $p_{e}{ }^{*}$ as the optimal recycling price of the recycling center, then when:

$$
\partial \prod_{m} / \partial p_{e}=0, p_{e}^{*}=\frac{\sum_{i=1}^{2}\left[\frac{3 \gamma_{i} w_{i}}{2}-\gamma_{i} p_{0}-\beta_{i} c_{i}-\alpha_{i} \theta_{i}+p_{0} \beta_{i}-\frac{\left(1-\theta_{i}\right) \alpha_{i} \gamma_{i}}{2 \beta_{i}}\right]}{2 \sum_{i=1}^{2} \beta_{i}-\sum_{i=1}^{2} \frac{\gamma_{i}^{2}}{2 \beta_{i}}},
$$

$\prod_{m}$ arrives at its maximum. Substituting $p_{e}{ }^{*}$ into $p_{i}{ }^{*}=\left[w_{i} \beta_{i}+\gamma_{i} p_{e}-\left(1-\theta_{i}\right) \alpha_{i}\right] / 2 \beta_{i}$, then we can get the final optimal price $p_{i}^{* *}$ as $p_{i}{ }^{* *}=\left[w_{i} \beta_{i}+\gamma_{i} p_{e}{ }^{*}-\left(1-\theta_{i}\right) \alpha_{i}\right] / 2 \beta_{i}$. Substituting $p_{e}{ }^{*}$ and $p_{i}{ }^{* *}$ into Equations (11) and (12), the maximum profit value of the recycling center and TPR can be obtained under this strategy.

\subsubsection{Unify All the Prices}

On the other hand, another way for the recycling center to compete with the TPR to increase revenue is to unify all the recycling prices for the TPRs and consumers from the different regions. Compared with the strategy in Section 4.2.1, the recycling center in this strategy absolutely ignores the regional differences and factors between online and offline. On the one hand, for recycling centers, although online channels are superior to the offline channels in terms of price, service, and environmental friendliness, many consumers are still unable to accept online channels because of traditional habits. It is important to know that consumers in many areas do not know much about Internet recycling. Therefore, the recycling center needs to strengthen publicity and improve services while increasing the recycling price of online channels as much as possible. On the other hand, if the online recycling price is set too high, it will lead to a series of serious problems. For example, this will lead to its own serious financial crisis and strong protest from the TPR. It may even be that the TPR will transfer its offline recyclable products to recycling centers through online channels for high online prices. Based on the above reasons, we selected the price transferred from the TPR to the recycling center as a critical point to unify all the recycling center's recycling prices. We assumed that $p_{T}\left(p_{T}=p_{e}=w_{i}\right)$ was the unified price of the recycling center. Then, the revenue function of TPR is:

$$
\prod_{i}=\left(p_{T}-p_{i}\right) d_{r i}=\left(p_{T}-p_{i}\right)\left[\left(1-\theta_{i}\right) \alpha_{i}+\beta_{i} p_{i}-\gamma_{i} p_{T}\right]
$$

Similar to the demonstration in Property 3 , after testifying, function $\prod_{i}$ is always concave with $p_{i}$, and the optimal recycling price $p_{i}^{*}$ of the TPR is $p_{i}{ }^{*}=\left[p_{T}\left(\beta_{i}+\gamma_{i}\right)-\left(1-\theta_{i}\right) \alpha_{i}\right] / 2 \beta_{i} ;$ moreover, the revenue function of recycling center is:

$$
\begin{aligned}
\prod_{m} & =\sum_{i=1}^{2}\left[\left(p_{0}-p_{T}-c_{i}\right) d_{e i}+\left(p_{0}-p_{T}\right) d_{r i}\right] \\
& =\sum_{i=1}^{2}\left\{\left(p_{0}-p_{T}-c_{i}\right)\left(\theta_{i} \alpha_{i}+\beta_{i} p_{T}-\gamma_{i} p_{i}\right)+\left(p_{0}-p_{T}\right)\left[\left(1-\theta_{i}\right) \alpha_{i}+\beta_{i} p_{i}-\gamma_{i} p_{T}\right]\right\}
\end{aligned}
$$

Property 7. The objective function $\prod_{m}$ is always concave with $p_{T}$.

The optimal recycling price formulated by the recycling center is:

$$
p_{T}{ }^{*}=\frac{\sum_{i=1}^{2}\left[\alpha_{i}\left(1-\theta_{i}\right)\left(\gamma_{i}-\beta_{i}\right)-\left(\gamma_{i}+\beta_{i}\right)\left(p_{0} \beta_{i}+\gamma_{i} c_{i}-p_{0} \gamma_{i}\right)-2 \beta_{i}\left(p_{0} \beta_{i}-c_{i} \beta_{i}-p_{0} \gamma_{i}-\alpha_{i}\right)\right]}{\sum_{i=1}^{2} 2\left(\gamma_{i}+3 \beta_{i}\right)\left(\gamma_{i}-\beta_{i}\right)}
$$


Substituting $p_{i}{ }^{*}=\left[p_{T}\left(\beta_{i}+\gamma_{i}\right)-\left(1-\theta_{i}\right) \alpha_{i}\right] / 2 \beta_{i}$, the final optimal recycling price $p_{i}{ }^{* *}$ of the TPR is $p_{i}{ }^{* *}=\left[p_{T}{ }^{*}\left(\beta_{i}+\gamma_{i}\right)-\left(1-\theta_{i}\right) \alpha_{i}\right] / 2 \beta_{i}$. Substituting $p_{T^{*}}$ and $p_{i}^{* *}$ into Equations (13) and (14) can also get the maximum profit value of the recycling center and the TPR under this strategy.

\subsubsection{Maximize Its Own Interests}

In this case, the recycling center not only occupies the dominant position relative to the TPR, but also has the absolute right of speech, which can guarantee the coordination and stability of the supply chain. Therefore, at this point, the recycling center will only consider promoting its own interests when making decisions and no longer worry about the impact of pricing on the TPR and consumers. Under this strategy, the revenue of the recycling center will reach its maximum value. However, the TPR's revenue will be significantly lower than the previous two strategies. Similarly, according to the reverse induction method, the revenue function aiming at the TPRs of different regions was studied first:

$$
\prod_{i}=\left(w_{i}-p_{i}\right) d_{r i}=-\beta_{i} p_{i}^{2}+\left[w_{i} \beta_{i}-\left(1-\theta_{i}\right) \alpha_{i}+\gamma_{i} p_{e}\right] p_{i}+\left[w_{i}\left(1-\theta_{i}\right) \alpha_{i}-w_{i} \gamma_{i} p_{e}\right]
$$

Similar to the demonstration in Section 4.2.1, the objective function $\prod_{i}$ is always concave with $p_{i}$. Setting $\partial \prod_{i} / \partial p_{i}=0$, the optimal pricing of TPR to $p_{i}$ is $p_{i}{ }^{*}=\left[w_{i} \beta_{i}+\gamma_{i} p_{e}-\left(1-\theta_{i}\right) \alpha_{i}\right] / 2 \beta_{i}$. At this point, the earnings of the TPR has arrived at its maximum. After observing the pricing of the two TPRs to $p_{i}$, the recycling center enacted a target pricing decision. The revenue function of the recycling center is:

$$
\begin{aligned}
& \underset{p_{i}^{*}}{\operatorname{Max}} \prod_{m}=\sum_{i=1}^{2}\left[\left(p_{0}-p_{e}-c_{i}\right) d_{e i}+\left(p_{0}-w_{i}\right) d_{r i}\right] \\
& =\sum_{i=1}^{2}\left\{\left(p_{0}-p_{e}-c_{i}\right)\left(\theta_{i} \alpha_{i}+\beta_{i} p_{e}-\gamma_{i} p_{i}^{*}\right)+\left(p_{0}-w_{i}\right)\left[\left(1-\theta_{i}\right) \alpha_{i}+\beta_{i} p_{i}{ }^{*}-\gamma_{i} p_{e}\right]\right\}
\end{aligned}
$$

Property 8. The objective function $\prod_{m}$ is always concave with $p_{e}$ and $w_{i}$.

Setting $\partial \prod_{m} / \partial w_{1}, \partial \prod_{m} / \partial w_{2}$ and $\partial \prod_{i} / \partial p_{e}$ as 0 , respectively, the optimal $w_{1}^{*}, w_{2}{ }^{*}$, and $p_{e}{ }^{*}$ formulated by the recycling center can be solved, and can make the earnings $\prod_{m}$ arrive at its maximum, that is:

$$
\begin{gathered}
p_{e}^{*}=\frac{\sum_{i=1}^{2}\left(p_{0} \beta_{i}-\alpha_{i} \theta_{i}-\beta_{i} c_{i}+\frac{c_{i} \gamma_{i}^{2}}{\beta_{i}}-\frac{p_{0} \gamma_{i}^{2}}{\beta_{i}}-\frac{\alpha_{i} \gamma_{i}\left(1-\theta_{i}\right)}{\beta_{i}}\right)}{\sum_{i=1}^{2}\left(2 \beta_{i}-\frac{2 \gamma_{i}^{2}}{\beta_{i}}\right)} \\
w_{i}^{*}=\frac{c_{i} \gamma_{i}+p_{0} \beta_{i}+2 \gamma_{i} p_{e}{ }^{*}-\alpha_{i}\left(1-\theta_{i}\right)-p_{0} \gamma_{i}}{2 \beta_{i}}
\end{gathered}
$$

Substituting $p_{e}{ }^{*}$ and $w_{i}{ }^{*}$ into $p_{i}{ }^{*}=\left[w_{i} \beta_{i}+\gamma_{i} p_{e}-\left(1-\theta_{i}\right) \alpha_{i}\right] / 2 \beta_{i}$, the final optimal recycling price can be obtained as $p_{i}{ }^{* *}=\left[w_{i}{ }^{*} \beta_{i}+\gamma_{i} p_{e}{ }^{*}-\left(1-\theta_{i}\right) \alpha_{i}\right] / 2 \beta_{i}$. Substituting into Equations (15) and (16), the maximum profits of recycling center and TPR can be obtained under this strategy.

Setting S1, S2, and S3 represent the three kinds of strategies in Sections 4.2.1-4.2.3, respectively, the optimal pricing and corresponding benefits of the recycling center, and the TPR under three strategies are classified in Table 3. 
Table 3. The optimal pricing and corresponding benefits.

\begin{tabular}{|c|c|c|c|}
\hline & S1 & S2 & S3 \\
\hline \multirow{2}{*}{$w_{i}^{*}$} & \multirow{2}{*}{$\frac{p_{0} \beta_{i}-\alpha_{i}}{2 \beta_{i}}$} & $\sum_{i=1}^{2}\left[\begin{array}{c}\alpha_{i}\left(1-\theta_{i}\right)\left(\gamma_{i}-\beta_{i}\right)-2 \beta_{i}\left(p_{0} \beta_{i}-c_{i} \beta_{i}-p_{0} \gamma_{i}-\alpha_{i}\right) \\
-\left(\gamma_{i}+\beta_{i}\right)\left(p_{0} \beta_{i}+\gamma_{i} c_{i}-p_{0} \gamma_{i}\right)\end{array}\right.$ & \multirow{2}{*}{$\frac{c_{i} \gamma_{i}+p_{0} \beta_{i}+2 \gamma_{i} p_{e}{ }^{*}-\alpha_{i}\left(1-\theta_{i}\right)-p_{0} \gamma_{i}}{2 \beta_{i}}$} \\
\hline & & $\sum_{i=1}^{2} 2\left(\gamma_{i}+3 \beta_{i}\right)\left(\gamma_{i}-\beta_{i}\right)$ & \\
\hline \multirow[t]{2}{*}{$p_{e}{ }^{*}$} & 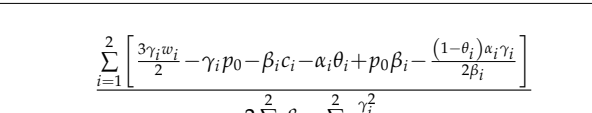 & 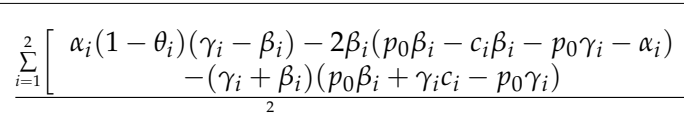 & \multirow[t]{2}{*}{$\sum_{i=1}^{2}\left(\begin{array}{c}p_{0} \beta_{i}-\alpha_{i} \theta_{i}-\beta_{i} c_{i}+\frac{c_{i} \gamma_{i}^{2}}{\beta_{i}} \\
-\frac{p_{0} \gamma_{i}^{2}}{\beta_{i}}-\frac{\alpha_{i} \gamma_{i}\left(1-\theta_{i}\right)}{\beta_{i}}\end{array}\right)$} \\
\hline & $2 \sum_{i=1}^{2} \beta_{i}-\sum_{i=1}^{2} \frac{\gamma_{i}^{2}}{2 \beta_{i}}$ & $\sum_{i=1}^{2} 2\left(\gamma_{i}+3 \beta_{i}\right)\left(\gamma_{i}-\beta_{i}\right)$ & \\
\hline$p_{i}^{* *}$ & $\frac{w_{i} \beta_{i}+\gamma_{i} p_{e}{ }^{*}-\left(1-\theta_{i}\right) \alpha_{i}}{2 \beta_{i}}$ & $\frac{p_{T^{*}}^{*}\left(\beta_{i}+\gamma_{i}\right)-\left(1-\theta_{i}\right) \alpha_{i}}{2 \beta_{i}}$ & $\frac{w_{i}^{*} \beta_{i}+\gamma_{i} p_{e}^{*}-\left(1-\theta_{i}\right) \alpha_{i}}{2 \beta_{i}}$ \\
\hline $\operatorname{Max} \prod_{m}$ & $\sum_{i=1}^{2}\left[\begin{array}{c}\left(p_{0}-p_{e}{ }^{*}-c_{i}\right)\left(\theta_{i} \alpha_{i}+\beta_{i} p_{e}{ }^{*}-\gamma_{i} p_{i}{ }^{* *}\right) \\
+\left(p_{0}-w_{i}{ }^{*}\right)\left[\left(1-\theta_{i}\right) \alpha_{i}+\beta_{i} p_{i}{ }^{* *}-\gamma_{i} p_{e}{ }^{*}\right]\end{array}\right.$ & $\sum_{i=1}^{2}\left\{\begin{array}{c}\left(p_{0}-p_{T}^{*}-c_{i}\right)\left(\theta_{i} \alpha_{i}+\beta_{i} p_{T}{ }^{*}-\gamma_{i} p_{i}{ }^{* *^{2}}\right) \\
+\left(p_{0}-p_{T}^{*}\right)\left[\left(1-\theta_{i}\right) \alpha_{i}+\beta_{i} p_{i}^{* *}-\gamma_{i} p_{T}{ }^{*}\right]\end{array}\right\}$ & $\sum_{i=1}^{2}\left\{\begin{array}{c}\left(p_{0}-p_{e}^{*}-c_{i}\right)\left(\theta_{i} \alpha_{i}+\beta_{i} p_{e}^{*}-\gamma_{i} p_{i}{ }^{*}\right) \\
+\left(p_{0}-w_{i}^{*}\right)\left[\left(1-\theta_{i}\right) \alpha_{i}+\beta_{i} p_{i}^{*}-\gamma_{i} p_{e}{ }^{*}\right]\end{array}\right.$ \\
\hline $\operatorname{Max} \prod_{i}$ & $\begin{array}{l}-\beta_{i} p_{i}^{* *^{2}}+\left[w_{i}^{*}\left(1-\theta_{i}\right) \alpha_{i}-w_{i}^{*} \gamma_{i} p_{e^{*}}\right] \\
\quad+\left[w_{i}^{*} \beta_{i}-\left(1-\theta_{i}\right) \alpha_{i}+\gamma_{i} p_{e}^{*}\right] p_{i}^{* *}\end{array}$ & $\left(p_{T}^{*}-p_{i}^{* *}\right)\left[\left(1-\theta_{i}\right) \alpha_{i}+\beta_{i} p_{i}^{* *}-\gamma_{i} p_{T}^{*}\right]$ & $\begin{array}{l}-\beta_{i} p_{i}^{*^{2}}+\left[w_{i}^{*}\left(1-\theta_{i}\right) \alpha_{i}-w_{i}^{*} \gamma_{i} p_{e}{ }^{*}\right] \\
\quad+\left[w_{i}^{*} \beta_{i}-\left(1-\theta_{i}\right) \alpha_{i}+\gamma_{i} p_{e}{ }^{*}\right] p_{i}{ }^{*}\end{array}$ \\
\hline
\end{tabular}




\section{Example Analysis}

According to the above study, we believe that in the dual-channel reverse supply chain, the index of consumer's sustainable awareness $\theta_{i}$ and sustainable logistics $\operatorname{cost} c_{i}$ can affect the optimal pricing strategy and the maximum benefit of the recycling center and TPR. Due to the uneven development of many countries including China, whether the basic value or the rate of change of $\theta_{i}$ and $c_{i}$ among the different regions of the country are different, so the recycling center should adjust the pricing strategy according to timely regional changes after introducing the online channel. Therefore, in this section, we conducted example analysis aiming at the change of $\theta_{i}$ and $c_{i}$. With the proving of the previous research conclusions, at the same time we also hoped to find the influence rule of the factors in the reverse supply chain of the different regions.

As one of the largest enterprises of "Internet + recycling" in China, Loving Recycling has developed rapidly in recent years. It recycles more than 5 million mobile phones each year, accumulating more than $\$ 130$ million in financing [30]. So, for the settings of some of the parameters in the numerical example, we referred to the related information on the iPhone 6 released by Loving Recycling [48]. For example, for the benefit of recycling each cell phone $p_{0}$, we assumed $p_{0}=1500$. In addition, for data between different urban areas, generally we assumed $a_{1}=a_{2}=2000, \beta_{1}=\beta_{2}=6$, and $\gamma_{1}=\gamma_{2}=4$. In addition, we assumed that the TPR of City A was TPR1 and the TPR of City A was TPR2. For the data that reflected the difference, we assumed that $\theta_{i}$ was floating up and down from 0.3 to 0.7 , because at present in most Chinese cities the development of online recycling is still in its infancy. Only in the most developed cities (such as Beijing, Shanghai) do people have sustainable awareness. The change of $c_{i}$ is floating in the range of $6 \sim 14$ due to the higher cost for online channels in some undeveloped and remote areas of the center.

\section{1. $\theta$ Analysis}

First of all, we analyzed the situation where only B city consumers improved their sustainable awareness. With the rapid development of e-commerce in city B, $\theta_{2}$ increased from 0.3 to 0.7 step by step. Reaching 0.7 means that $70 \%$ of the city's consumers will choose online channels to recycle their old iPhone 6. Next, we used the control variable method to ensure $\theta_{1}=0.3$ and $c_{1}=c_{2}=10$ to prevent interference in the results of an example. Finally, according to the three strategies in Section 4.2, we obtained the profits and optimal pricing of the recycling center and the two TPRs, respectively, in Tables 4-6, and obtained the line chart of the recycling center and the two TPRs' profit changes, respectively, for comparison.

Table 4 . The effect of $\theta_{2}$ on decisions by applying strategy 1 .

\begin{tabular}{ccccccccc}
\hline $\boldsymbol{\theta}_{\mathbf{2}}$ & $\boldsymbol{p}_{\boldsymbol{e}}$ & $\boldsymbol{w}_{\mathbf{1}}$ & $\boldsymbol{w}_{\mathbf{2}}$ & $\boldsymbol{p}_{\mathbf{1}}$ & $\boldsymbol{p}_{\mathbf{2}}$ & $\Pi_{\mathbf{1}}$ & $\Pi_{\mathbf{2}}$ & $\Pi_{\boldsymbol{m}}$ \\
\hline 0.3 & 503.83 & 583.33 & 583.33 & 342.94 & 342.94 & $346,719.31$ & $346,719.31$ & $7,084,434.19$ \\
0.4 & 497.58 & 583.33 & 583.33 & 340.86 & 357.53 & $352,755.06$ & $305,927.39$ & $7,118,271.01$ \\
0.5 & 491.32 & 583.33 & 583.33 & 338.77 & 372.11 & $358,852.67$ & $267,696.00$ & $7,152,761.25$ \\
0.6 & 485.07 & 583.33 & 583.33 & 336.69 & 386.69 & $364,992.67$ & $232,007.67$ & $7,188,711.22$ \\
0.7 & 478.82 & 583.33 & 583.33 & 334.61 & 401.27 & $371,184.75$ & $198,871.42$ & $7,225,345.22$ \\
\hline
\end{tabular}

Table 5. The effect of $\theta_{2}$ on decisions by applying strategy 2 .

\begin{tabular}{ccccccccc}
\hline $\boldsymbol{\theta}_{\mathbf{2}}$ & $\boldsymbol{p}_{\boldsymbol{e}}$ & $\boldsymbol{w}_{\mathbf{1}}$ & $\boldsymbol{w}_{\mathbf{2}}$ & $\boldsymbol{p}_{\mathbf{1}}$ & $\boldsymbol{p}_{\mathbf{2}}$ & $\Pi_{\mathbf{1}}$ & $\Pi_{\mathbf{2}}$ & $\Pi_{\boldsymbol{m}}$ \\
\hline 0.3 & 505.45 & 505.45 & 505.45 & 304.54 & 304.54 & $242,184.95$ & $242,184.95$ & $7,152,211.42$ \\
0.4 & 503.18 & 503.18 & 503.18 & 302.65 & 319.32 & $241,273.69$ & $202,834.35$ & $7,184,081.02$ \\
0.5 & 500.91 & 500.91 & 500.91 & 300.76 & 334.09 & $240,364.14$ & $166,970.14$ & $7,216,006.06$ \\
0.6 & 498.64 & 498.64 & 498.64 & 298.87 & 348.87 & $239,456.31$ & $134,592.31$ & $7,248,027.26$ \\
0.7 & 496.36 & 496.36 & 496.36 & 296.97 & 363.63 & $238,546.21$ & $105,698.21$ & $7,280,096.97$ \\
\hline
\end{tabular}


Table 6. The effect of $\theta_{2}$ on decisions by applying strategy 3 .

\begin{tabular}{ccccccccc}
\hline $\boldsymbol{\theta}_{\mathbf{2}}$ & $\boldsymbol{p}_{\boldsymbol{e}}$ & $\boldsymbol{w}_{\mathbf{1}}$ & $\boldsymbol{w}_{\mathbf{2}}$ & $\boldsymbol{p}_{\mathbf{1}}$ & $\boldsymbol{p}_{\mathbf{2}}$ & $\Pi_{\mathbf{1}}$ & $\Pi_{\mathbf{2}}$ & $\Pi_{\boldsymbol{m}}$ \\
\hline 0.3 & 515.00 & 480.00 & 480.00 & 295.00 & 295.00 & $205,350.00$ & $205,350.00$ & $7,158,900.00$ \\
0.4 & 510.00 & 476.67 & 493.33 & 291.67 & 316.67 & $205,353.70$ & $187,263.13$ & $7,187,914.30$ \\
0.5 & 505.00 & 473.33 & 506.67 & 288.33 & 338.34 & $205,346.30$ & $170,020.03$ & $7,218,906.40$ \\
0.6 & 500.00 & 470.00 & 520.00 & 285.00 & 360.00 & $205,350.00$ & $153,600.00$ & $7,251,900.00$ \\
0.7 & 495.00 & 466.67 & 533.33 & 281.67 & 381.67 & $205,353.70$ & $138,013.63$ & $7,316,762.80$ \\
\hline
\end{tabular}

According to the data presented in Tables $4-6$, it can be seen that:

Result 1: under S1, with the improvement of $\theta_{2}, p_{e}$ and $p_{1}$ are monotonically decreasing and $p_{2}$ is monotonically increasing; for TPR2, the difference value between $w_{2}$ and $p_{2}$ decreases gradually with the improvement of $\theta_{2}$; for TPR1, the difference value between $w_{1}$ and $p_{1}$ increases gradually with the improvement of $\theta_{2}$.

Result 2: under S2, with the improvement of $\theta_{2}, p_{\mathrm{e}}$ and $p_{1}$ are monotonically decreasing, $p_{2}$ is monotonically increasing, and the decreasing amplitude of $w_{1}$ and $w_{2}$ is minimal; for TPR2, the difference value between $w_{2}$ and $p_{2}$ decreases gradually with the improvement of $\theta_{2}$; for TPR1, the difference value between $w_{1}$ and $p_{1}$ decreases slightly with the improvement of $\theta_{2}$.

Result 3: under S3, with the improvement of $\theta_{2}, p_{e}$ and $p_{1}$ are monotonically decreasing, $w_{2}$ and $p_{2}$ are monotonically increasing, and the decreasing amplitude of $w_{1}$ is minimal; for TPR2, the difference value between $w_{2}$ and $p_{2}$ gradually decreases with the improvement of $\theta_{2}$; for TPR1, the difference value between $w_{1}$ and $p_{1}$ keeps unchanged with the improvement of $\theta_{2}$.

Result 4: comparing Tables 4-6, it was found that for TPR1, the difference value between $w_{1}$ and $p_{1}$ was always far higher than that of $\mathrm{S} 2$ and $\mathrm{S} 3$ under $\mathrm{S} 1$.

Result 5: comparing Table 5 with Table 6, it was found that for TPR2, the difference value between $w_{1}$ and $p_{1}$ was greater than S3 when $\theta_{2}$ was lower under $\mathrm{S} 2$, and when $\theta_{2}$ was higher, the difference value between $w_{1}$ and $p_{1}$ was less than $\mathrm{S} 3$ under $\mathrm{S} 2$.

Figure 3 first shows that with the improvement of $\theta_{2}$, its revenue steadily increased regardless of what strategy the recycling center adopted. This is because more consumers will choose to recycle waste products online through recycling centers with the promotion of sustainable awareness and online recycling channel preferences.

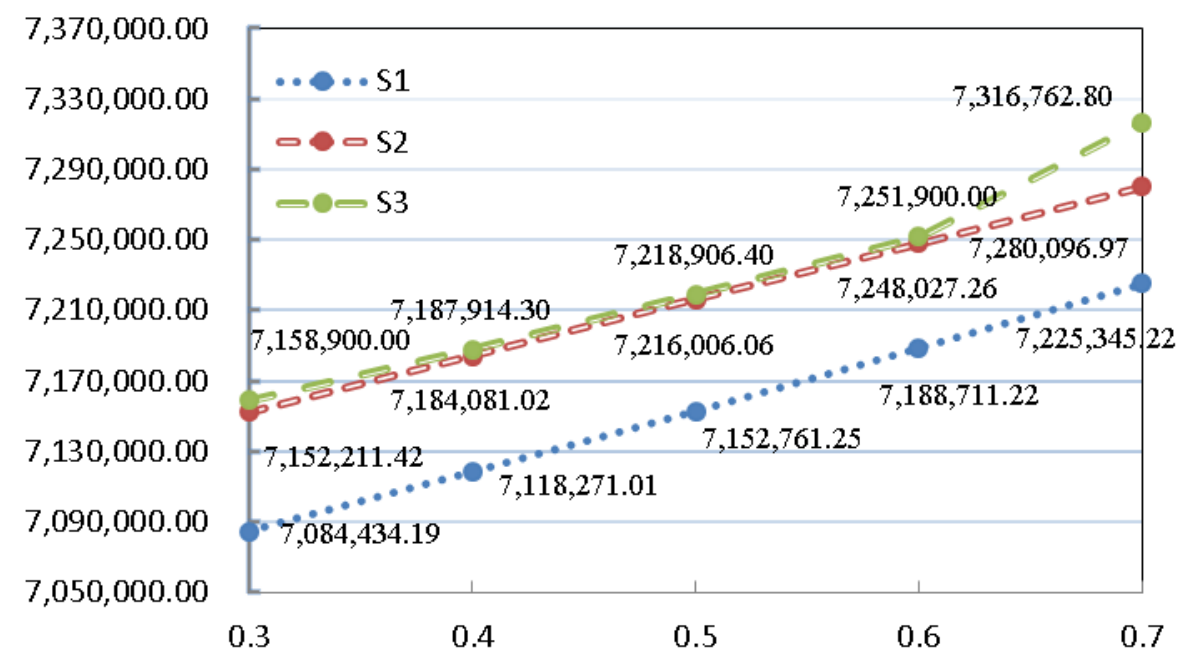

Figure 3. The benefits of the recycling center under three strategies as $\theta_{2}$ increases.

Secondly, comparing the three types of strategies that can be adopted by the recycling center, it shows that the income obtained was obviously lower than the other two strategies when S1 was 
adopted, that is, when the transfer price of the TPR is guaranteed to be unchanged when the online channel is introduced. Comparing the results of 1,2, and 3, it was found that in the early stages of the introduction of the online channel, the recycling center will keep the transfer price unchanged for the stability of the supply chain and avoid conflict with the TPR1. On the one hand, the transfer price of the recycling center under S1 is much higher than the transfer price under S2 and S3; on the other hand, the offline recycling price under S1 and the online recycling price under S2 and S3 are relatively close, resulting in the lowest revenue of the recycling center under this strategy. With the improvement of online channels, the promotion of publicity and promotion of service, the recycling center can gradually adopt S2 or S3 to increase revenue.

Furthermore, when $\theta_{2}$ was lower, the returns of S2 and S3 adopted by the recycling center were very close, and when a higher level was reached, the sensitivity of the return of the recycling center under S3 was significantly higher than that under S2. Combined with Results 2 and 3, it was found that the transfer price of the recycling center under S2 was higher than that under S3, and the online recycling price was lower than that under S3, which led to the close return of the recycling center under the two types of strategy; on the other hand, when it was higher, the online recycling prices under S2 and S3 were very close, and the transfer price in the city B under S2 was obviously lower than that under S3, but the transfer price in the city A was still higher than that under S3, which has led to a marked increase in the sensitivity under $\mathrm{S} 3$ to the recycling ratio of the recycling center under S2. This is because, at the early stage of the introduction of the online channel when $\theta_{2}$ was lower, S2 can strengthen the competition between the online and offline channels and keeps the return of the recycling center at a higher level; while $\theta_{2}$ was higher, the share of the online channels was obviously higher than the offline channel, and under the premise that the recycling center could have lowered the TPR1 transfer price, if it still kept the price of all channels the same under S2, that is to increase its cost, which would lead to revenue to the degree of sensitivity of $\theta_{2}$ lower than S3.

Figure 4 shows that with the improvement of $\theta_{2}$, the revenue of TPR2 will gradually decrease all the same no matter what strategy the recycling center adopts. This is because the consumers would still choose offline recycling channels despite the fact that it is not easy for them to change their traditional habits and do not understand online channels at first. However, with the spread of online channels in city B, the security of the offline channels, the low level of service and the non-environmental protection of the processing are beginning to appear, and the consumers gradually choose online channels, which directly leads to the reduction of the consumers who choose the recycling channels offline in the city. Results 1,2 and 3 all showed that $p_{2}$ always increased with the improvement of $\theta_{2}$, and the transfer price of the recycling center was very small, which led to the decrease of its revenue.

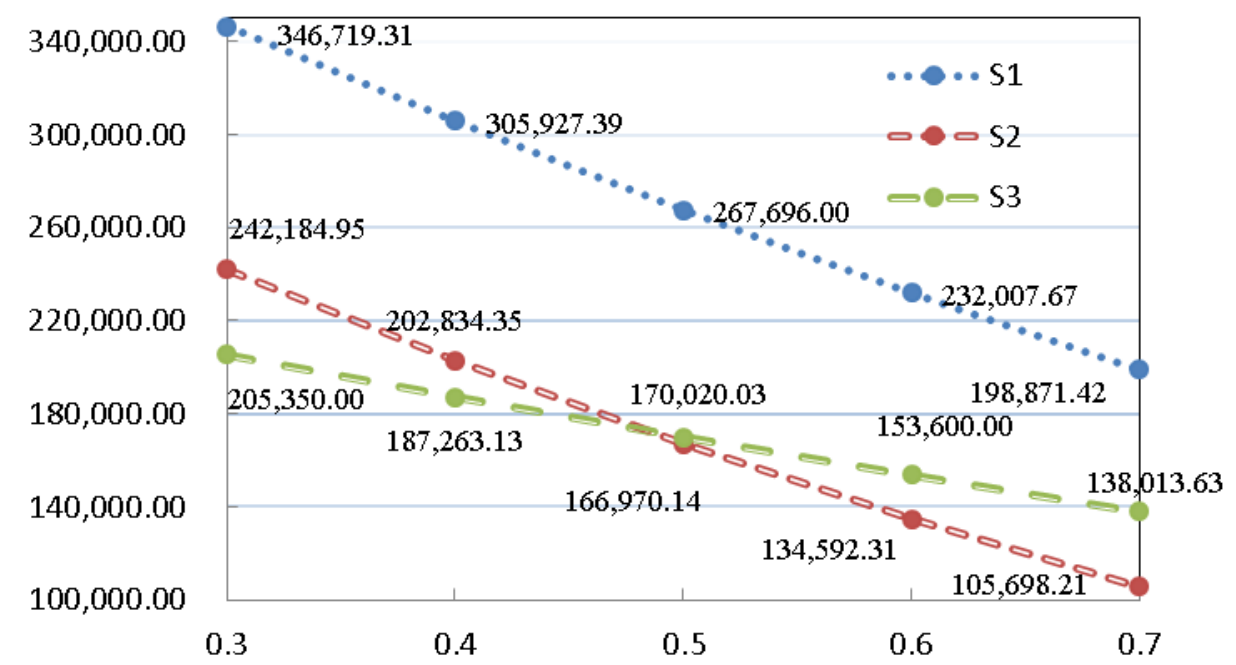

Figure 4. The benefits of the third-party recycler (TPR) 2 under the three strategies as $\theta_{2}$ increases. 
In addition, when $\mathrm{S} 1$ was adopted by the recycling center, TPR2's revenue was much higher than the other two strategies. This is because in order to maintain the stability of the system, the recycling center maintains a high and constant transfer price to the TPR product under this strategy, and then minimizes the impact of the introduction of the online channel on the TPR revenue.

Finally, comparing S2 and S3, it was found that when $\theta_{2}$ was at a lower level, the revenue of TPR2 under S2 was higher than that under S3; when $\theta_{2}$ was at a higher level, the revenue of TPR2 under S2 was lower than $\mathrm{S3}$. From Result 5, it was found that when $\theta_{2}$ was at a higher level, the difference value between the transfer price and the recycling price under S2 was greater than that under S3, which was because although the recycling center used the S2 and TPR to compete in price, the development of the online channel is still in its infancy, and the impact on TPR2 is limited, it results in the higher overall income of TPR2 under this strategy. When $\theta_{2}$ was at a higher level, the difference value between the transfer price and the recycling price under S2 was less than that under S3. This is because the ratio of consumers who choose the online channels is far higher than that of the offline channels. If the recycling center still uses S2 at this time, the transfer price of TPR2 will be kept down, which would lead to the lower overall revenue.

Figure 5 shows that when the $\theta_{2}$ level of city B increases, the revenue of TPR 1 will also be affected. This is an interesting phenomenon, because the changes of $\theta_{2}$ not only affect the decision of TPR2, but also make the recycling center change its online recycling price and transfer price, and then make TPR1 adjust the pricing.

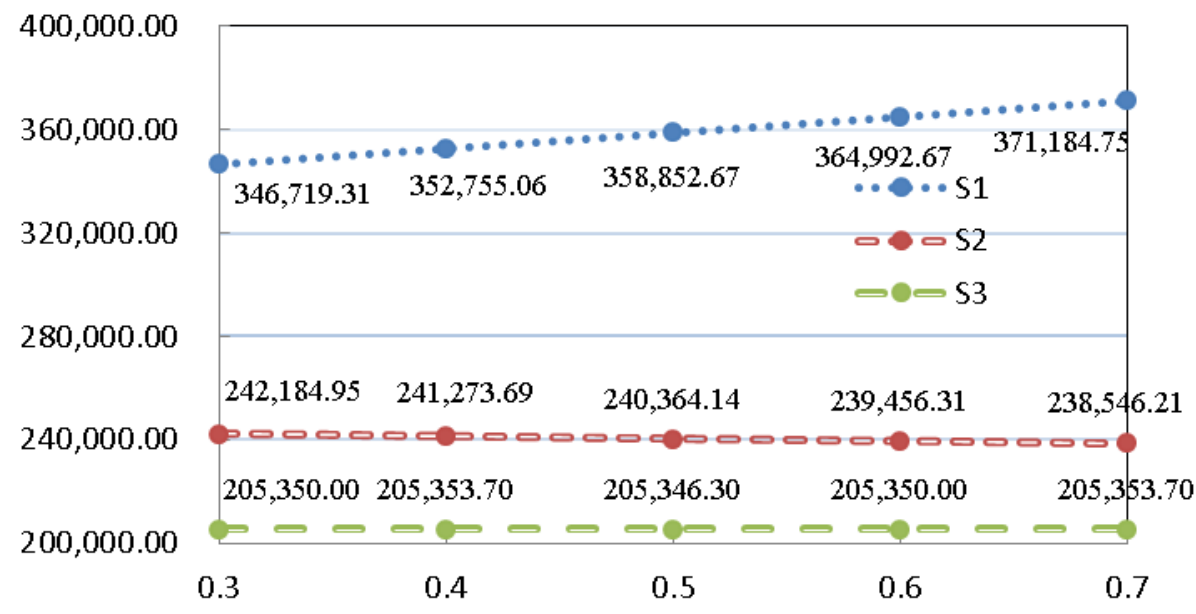

Figure 5. The benefits of TPR1 under three strategies as $\theta_{2}$ increases.

Further comparing the three types of strategies, it was found that TPR1 had the highest revenue under S1, and it kept steady growth with the improvement of $\theta_{2}$. This was due to the constant increase of $\theta_{2}$ in the city B under S1, but the recycling center kept the price of all the lines unchanged in order to keep the supplying chain system stable. At the same time, with the decrease of the TPR1 recycling price, the revenue of TPR 1 increased. In addition, according to Result 4, we also found that due to the high transfer price, the difference value between the transfer price and the recycling price of TPR1 under S1 was always far higher than S2 and S3, which led to the highest revenue of TPR1 under S1.

In addition, it was found that the improvement of $\theta_{2}$ under S2 will make TPR1's revenue gradually decrease. This is because in the price competition strategy, the improvement of $\theta_{2}$ decreases the quantity of the offline recycling in the two cities. On the one hand, it forces TPR2 to improve the recycling price; on the other hand, the recycling center is constantly reducing the transfer price. Although the reduction in online recycling prices can make TPR1 slightly lower the recycling price, the difference value between the transfer price and the recycling price is still decreasing, as shown in the result of 2 . This leads to the gradual decrease of TPR1's revenue under S2 with the increase of $\theta_{2}$. 
Finally, with the improvement of $\theta_{2}$, the revenue of TPR1 under S3 fluctuates smoothly. This is because in the Stackelberg game, the recycling center always responds in time according to the decision of TPR2 and the change of $\theta_{2}$, and it has little influence on TPR1.

\subsection{Sustainable Logistics Costs (c) Analysis}

In this section, we analyzed the influence of the change of sustainable logistics $\operatorname{costs} c_{2}$ of electronic channels in city B on the members of the supply chain under three different strategies. The development of logistics in China also has serious regional differences. For example, in the south-eastern coastal area of China, if you buy something online or recycle used products, the logistics cost can be very low or even free. However, in the vast north-west of China, logistical costs are relatively high, and even require additional costs. On the other hand, in recent years, China's logistics industry has developed rapidly, and the sustainable logistics cost has gradually reduced. Based on this, we assumed that $\theta_{1}=\theta_{2}=0.3$, and $c_{1}=0.6$ as the fixed value, and $c_{2}$ was reduced from 14 to 6 . Similar to the research in Section 5.1, we present the data of the examples in three Tables 7-9 and drew a line chart for the changes of the income of different supply chain members.

Table 7. The effect of $c_{2}$ on decisions by applying strategy 1 .

\begin{tabular}{ccccccccc}
\hline$c_{\mathbf{2}}$ & $p_{\boldsymbol{e}}$ & $w_{\mathbf{2}}$ & $w_{\mathbf{2}}$ & $p_{\mathbf{1}}$ & $p_{\mathbf{2}}$ & $\Pi_{\mathbf{1}}$ & $\Pi_{\mathbf{2}}$ & $\Pi_{\boldsymbol{m}}$ \\
\hline 14 & 503.83 & 583.33 & 583.33 & 342.94 & 342.94 & $346,719.31$ & $346,719.31$ & $7,084,434.20$ \\
12 & 504.39 & 583.33 & 583.33 & 343.13 & 343.13 & $346,181.04$ & $346,181.04$ & $7,089,528.97$ \\
10 & 504.95 & 583.33 & 583.33 & 343.32 & 343.32 & $345,643.20$ & $345,643.20$ & $7,094,628.32$ \\
8 & 505.51 & 583.33 & 583.33 & 343.50 & 343.50 & $345,105.78$ & $345,105.78$ & $7,099,701.25$ \\
6 & 506.08 & 583.33 & 583.33 & 343.69 & 343.69 & $344,559.19$ & $344,559.19$ & $7,104,809.76$ \\
\hline
\end{tabular}

Table 8. The effect of $c_{2}$ on decisions by applying strategy 2 .

\begin{tabular}{ccccccccc}
\hline$c_{\mathbf{2}}$ & $\boldsymbol{p}_{\boldsymbol{e}}$ & $\boldsymbol{w}_{\mathbf{2}}$ & $\boldsymbol{w}_{\mathbf{2}}$ & $\boldsymbol{p}_{\mathbf{1}}$ & $\boldsymbol{p}_{\mathbf{2}}$ & $\Pi_{\mathbf{1}}$ & $\Pi_{\mathbf{2}}$ & $\Pi_{\boldsymbol{m}}$ \\
\hline 14 & 505.45 & 505.45 & 505.45 & 304.54 & 304.54 & $242,184.95$ & $242,184.95$ & $7,152,211.41$ \\
12 & 505.82 & 505.82 & 505.82 & 304.85 & 304.85 & $242,333.65$ & $242,333.65$ & $7,157,048.25$ \\
10 & 506.18 & 506.18 & 506.18 & 305.15 & 305.15 & $242,478.37$ & $242,478.37$ & $7,161,880.25$ \\
8 & 506.55 & 506.55 & 506.55 & 305.46 & 305.46 & $242,627.15$ & $242,627.15$ & $7,166,720.89$ \\
6 & 506.91 & 506.91 & 506.91 & 305.76 & 305.76 & $242,771.96$ & $242,771.96$ & $7,171,556.77$ \\
\hline
\end{tabular}

Table 9. The effect of $c_{2}$ on decisions by applying strategy 3 .

\begin{tabular}{ccccccccc}
\hline$c_{\mathbf{2}}$ & $p_{\boldsymbol{e}}$ & $w_{\mathbf{1}}$ & $w_{\mathbf{2}}$ & $p_{\mathbf{1}}$ & $\boldsymbol{p}_{\mathbf{2}}$ & $\Pi_{\mathbf{1}}$ & $\Pi_{\mathbf{2}}$ & $\Pi_{\boldsymbol{m}}$ \\
\hline 14 & 514.75 & 478.50 & 481.17 & 294.17 & 295.50 & $203,872.67$ & $206,836.38$ & $7,158,913.92$ \\
12 & 515.24 & 478.83 & 480.83 & 294.50 & 295.50 & $203,876.35$ & $206,094.37$ & $7,163,950.06$ \\
10 & 515.75 & 479.17 & 480.50 & 294.84 & 295.50 & $203,876.35$ & $205,350.00$ & $7,168,962.65$ \\
8 & 516.24 & 479.49 & 480.16 & 295.16 & 295.49 & $203,868.98$ & $204,610.67$ & $7,173,977.51$ \\
6 & 516.74 & 479.83 & 479.83 & 295.50 & 295.50 & $203,876.35$ & $203,876.35$ & $7,179,038.99$ \\
\hline
\end{tabular}

According to the data presented in Tables 7-9, it can be seen that:

Result 1: under S1, with the decrease of $c_{2}$, both $p_{e}, p_{1}$ and $p_{2}$ are monotonically increasing; for TPR2, the difference value between $w_{2}$ and P2 decreases gradually with the decrease of $c_{2}$; for TPR1, the difference value between $w_{1}$ and $p_{1}$ decreases gradually with the decrease of $c_{2}$.

Result 2: under S2, with the decrease of $c_{2}, w_{1}, w_{2}, p_{e}, p_{1}$ and $p_{2}$ are all monotonically increasing; for TPR2, the difference value between $w_{2}$ and $p_{2}$ gradually increases with the decrease of $c_{2}$; for TPR1, the difference value between $w_{1}$ and $p_{1}$ increases with the decrease of $c_{2}$.

Result 3: under S3, with the decrease of $c_{2}, p_{e}, w_{1}$ and $p_{1}$ are monotonically increasing, while $w_{2}$ is monotonically decreasing, and $p_{2}$ remains unchanged; for TPR2, the difference value between $w_{2}$ 
and $p_{2}$ decreases gradually with the decrease of $c_{2}$; for TPR1, the difference value between, $w_{1}$ and $p_{1}$ decreases with the decrease of $c_{2}$.

Result 4: comparing Tables 7-9, it is found that for TPR1, the difference value between, $w_{1}$ and $p_{1}$ is always higher than that of S2 and S3 under S1.

Figure 6 first shows that with the decrease of $c_{2}$, regardless of the strategy the recycling center adopts, its revenue increases steadily. This is because with the development of the urban logistics industry and the promotion of the enterprise logistics facilities, the logistical costs of the online channel are gradually reduced, which directly improves the revenue of the recycling center.

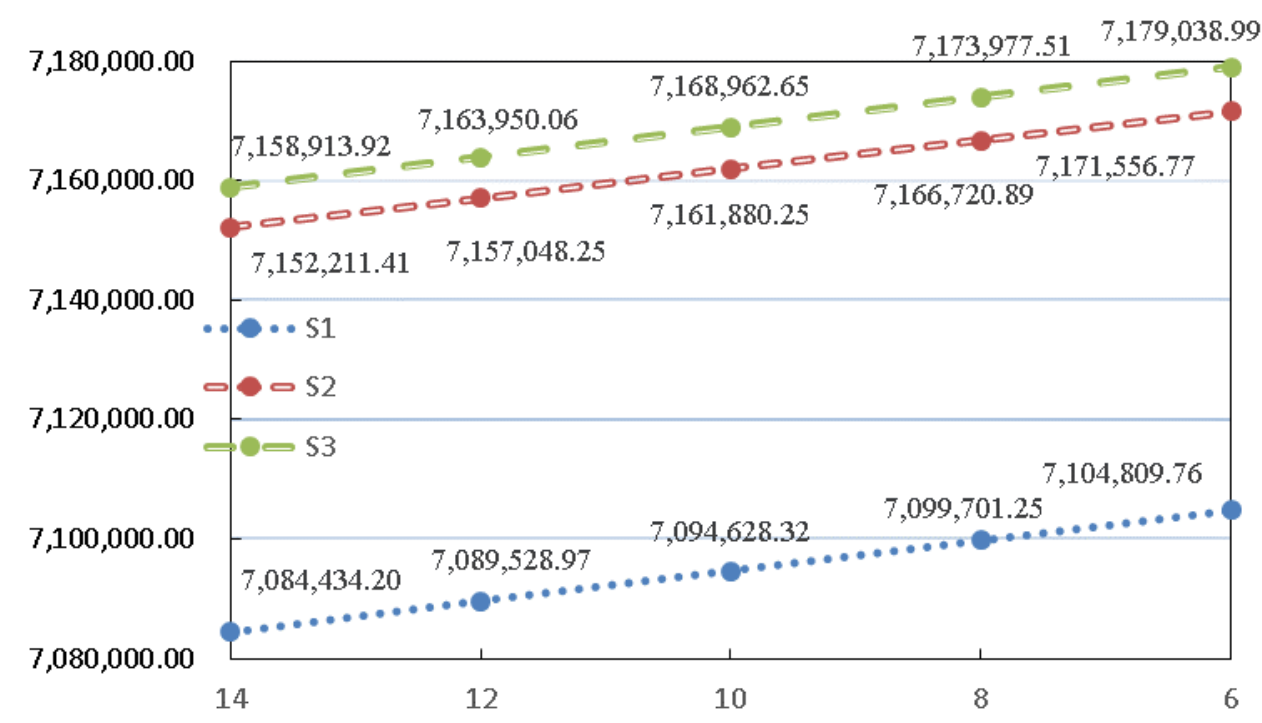

Figure 6. The benefits of the recycling center under three strategies as $c_{2}$ decreases.

Second, when the recycling center takes S1, its revenue is always lower than the other two strategies. Similar to the case in Figure 3, this is because under S1, the recycling center keeps high, constant transfer prices in order to reduce the conflict of the supply chain, which directly leads to the high cost of their own delivery. Despite the decrease in the cost of online channels, the total income has improved, but the revenue of the strategy is obviously lower than the other two strategies in cases of low consumer sustainable awareness $\left(\theta_{1}=\theta_{2}=0.3\right)$, the amount of online recycling is lower than that offline, and the low recycling price difference between the three types of strategies.

In addition, the revenue from the recycling center under S3 is always higher than that under S2. By comparing the different price levels of the recycling center under Result 2 and Result 3, it was found that in the case where the price of the online recycling was not very different, and the transfer price was much higher than that under S3 because the recycling center of S2 needs to unify all the prices. This directly results in less than S3 revenue under S2. As we studied the development of $c_{2}$ under the hypothesis of the low consumer's sustainable awareness in the two cities, we could see that in this context, the reduction of $c_{2}$ did not affect the decision making of the recycling center.

Figure 7 shows that as the recycling center takes S1 and S3, the revenue of the TPR2 will gradually decrease with the decrease of $c_{2}$, and when the recycling center takes S2, the revenue of the TPR2 will increase gradually. According to Result 1 , it was found that with the decrease of $\mathrm{S} 1$, the $p_{2}$ is increasing while $w_{2}$ is unchanged, and the revenue of TPR2 decreases. This is because the reduction in this strategy can help the recycling center raise online recycling prices to enhance online recycling. All of these pose a threat to TPR2, then it can only raise the price offline to compete with the recycling center and result in a decrease in revenue. This reason can also explain why the TPR's revenue will decrease in S3. In addition, according to Result 2, although it has been reduced, the recycling center under S2 raises the recycling price online at the same time increasing the recycling price offline in order to unify all the prices. This leads to the gradual increase of TPR2's revenue under this strategy. 


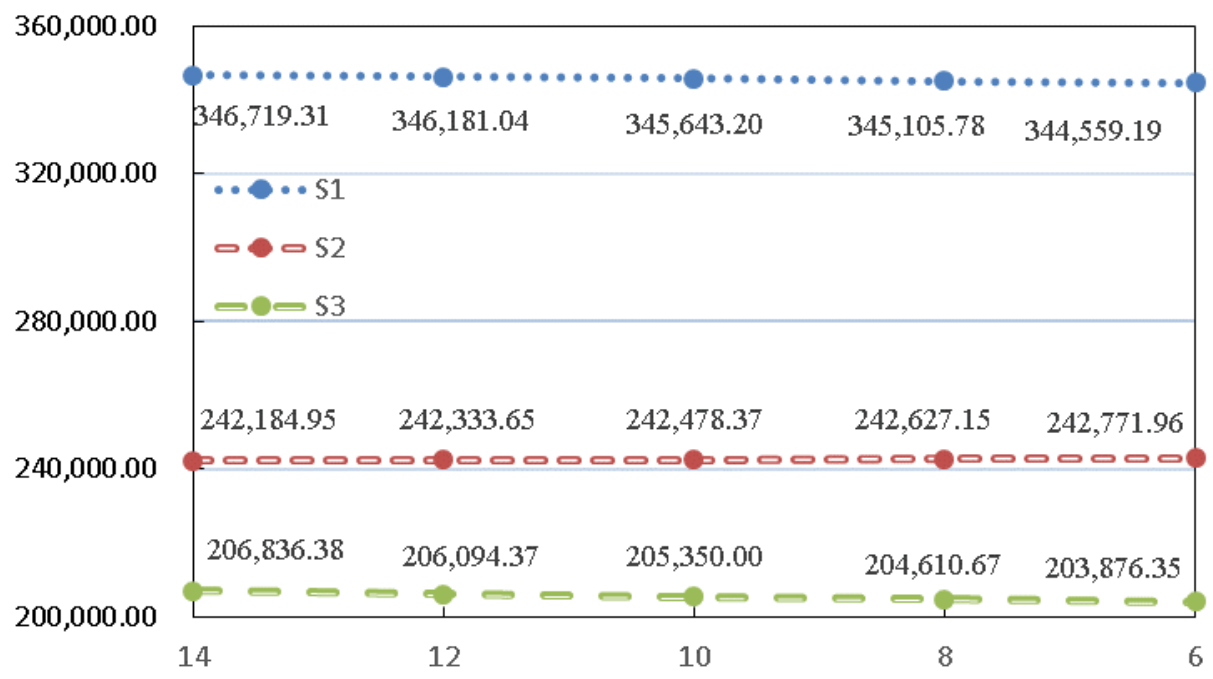

Figure 7. The benefits of TPR2 under three strategies as $c_{2}$ decreases.

In addition, when S1 was adopted in the recycling center, the revenue of TPR2 was much higher than the other two strategies. Similar to the interpretation of Figure 4, this was due to the high transfer price caused by the recycling center at the beginning of the introduction of the online channel to reduce the conflict with TPR.

Finally, by comparing S2 and S3, it was found that the revenue of TPR2 was much higher than that of S3 under S2. The comparison between Results 2 and 3 showed that the recycling price of TPR2 was relatively close across the two strategies, and under S2 the transfer price was much higher than that of S3 because of the unification of all the prices of the recycling center, which also led to the higher revenue of TPR2 under S2.

Figure 8 shows that when city B's online logistics level was raised and the cost reduced, it will not only affect the revenue of the recycling center and TPR2, but also the revenue of TPR1. According to the results, this reduction changes the online recycling and transfer prices of the recycling center and the recycling price of TPR2, thus making TPR1 adjust its pricing strategies.

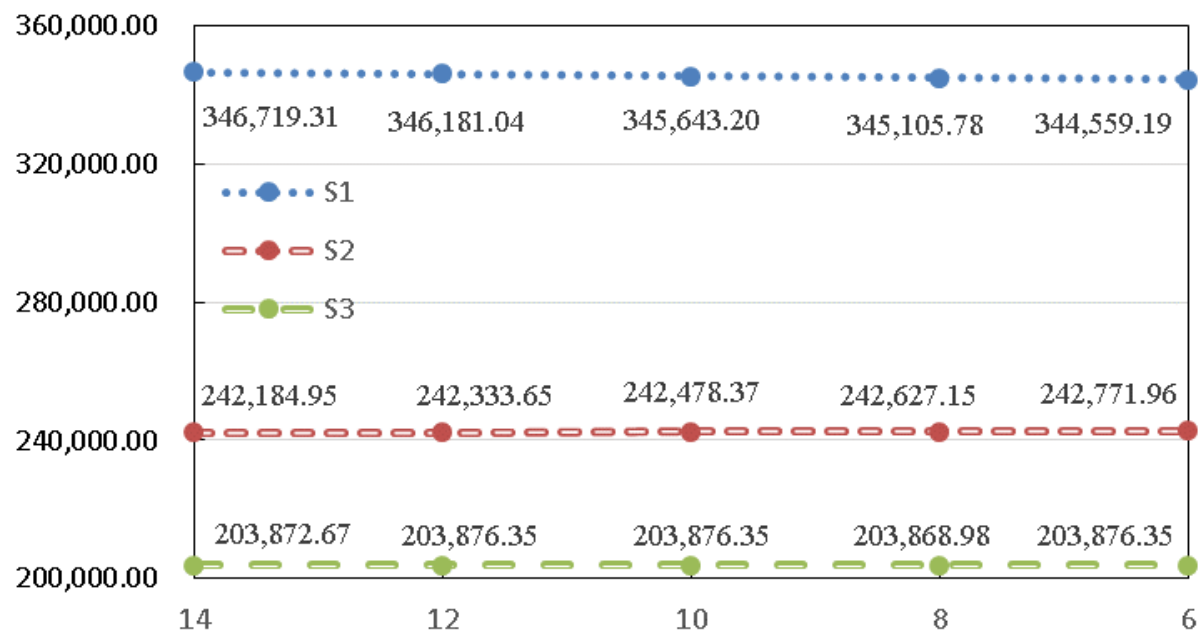

Figure 8. The benefits of TPR1 under three strategies as $c_{2}$ decreases.

Further comparing the three kinds of strategies synthetically, we found that under S1, TPR1 had the highest revenue and decreased with the decrease of $c_{2}$. According to Result 1 , we can see that under the strategy, the transfer price of TPR1 remains unchanged, and the recycling price decreased, 
resulting in a decline in its revenue. Similar to the explanation for the decrease in revenue of TPR2 in Figure 7, the decrease in the revenue of TPR1 was also due to the decrease of $c_{2}$, leading to the recycling center's increase in online prices, thus making TPR1 raise the recycling price. When the transfer price remained unchanged, the recycling price led to the decrease of its revenue.

In addition, under S2, the revenue of TPR1 will increase slightly with the decrease of $c_{2}$. According to Result 4, although the transfer price and recycling price of TPR1 were higher in this strategy, the difference value between the two also increased with the decrease of $c_{2}$ as the transfer price increased, which leads to an increase in the revenue of the TPR.

Finally, the revenue of TPR1 under S3 fluctuates smoothly with the decrease of $c_{2}$. Similar to the explanation in Figure 5, this is because in the Stackelberg game between the members of the supplying chain, the recycling center can always respond in time according to the decision of TPR2 and change of $c_{2}$, and the impact on TPR1 is relatively small.

\subsection{Results and Discussion}

In this subsection, we summarize and compare the simulation results of the two parts of Sections 5.1 and 5.2 .

First, according to the 5.1 simulation on the recycling center, we found that when the sustainable awareness of the consumers in city B is improved, the revenue will be increased steadily regardless of the kind of strategy it follows. In addition, in the initial stage of its introduction of online channels, although it will have lower revenue, S1 should be chosen for channel stability. The choice of S3 will be better than S2 when the consumer's sustainable awareness is raised to a higher level, which means that the fierce price competition does not generate a profit. On the other hand, it is interesting that the optimal strategy of the recycling center is also for TPR2. For TPR2, the sustainable awareness of consumers in city B is bound to reduce their earnings. In the initial stage of the introduction of the online channel, when the recycling center selects S1, TPR2 can maximize the revenue in this strategy, and when the recycling center selects S3 with the increase of $\theta_{2}$, this is also the best strategy for the TPR2, so the selection of S3 is also more conducive to the stability of the system. Finally, for TPR1, when S1 and S2 are selected by the recycling center, the TPR1 will achieve a higher return when playing with TPR2. This phenomenon is similar to the proverb "When shepherds quarrel, the wolf has a winning game". When the recycling center chooses S3 and achieves a balanced state with TPR2, the revenue of TPR1 is the lowest.

Second, according to the result of 5.2, when the logistical costs of city B decreases, regardless of what strategy the recycling center adopts, the revenue will steadily increase. In addition to choosing S1 at the initial stage of the introduction of online channels, choosing S3 is obviously better than S2. On the other hand, for TPR1 and TPR2, when the recycling center chooses S1, the revenue is the highest, and when the recycling center chooses S3, the revenue is the lowest. In particular for TPR1, although the cost of online logistics is reduced in city B it also needs to adjust its own pricing decisions at any time according to the decision of the recycling center and the changes in $c_{2}$. For example, under S3, TPR1 needs to raise the price of recycling continuously to achieve stability of revenue.

Finally, through the comparison of the simulation results in Sections 5.1 and 5.2, it was found that although all the revenue of the recycling center could be improved, the recycling of the online channel was directly widened and the impact of the logistics cost on the other TPR returns was less than that of improving the consumer's sustainable awareness. Therefore, the recycling center is flexible and scientific in terms of process optimization, channel promotion, and pricing decisions.

\section{Conclusions and Future Research}

\subsection{Conclusions and Managerial Implications}

This paper was inspired by the transformation of the recycling industry to "smart" and "intelligent". Under the background of "Internet + ", the pricing strategy of the node enterprises 
in the dual-channel reverse supply chain in different regions was studied. First of all, we set up two kinds of pricing models of differentiated pricing and unified pricing in the traditional mode, and compared them. In addition, we analyzed the influence of different regional difference factors on the pricing of the recycling center and TPR, and established three kinds of pricing strategy models aimed at the domination of different enterprises in the supply chain and their conflict. The conclusions and managerial implications of this paper have demonstrated that:

(1) In the traditional recycling mode, when making decisions for TPRs in different regions, it can bring more benefits for the recycling center by choosing the differential pricing strategy rather than unified pricing. However, as of now, the recycling center only stays at the differential pricing of wasted products when pricing the transfer price. Therefore, we recommend that recycling centers can differentiate pricing for different regional developments.

(2) We propose three pricing strategies for the recycling center to maximize their benefits after introducing the online channel. After numerical verification, we found that S3 always yielded the maximum benefit. However, at the beginning of the introduction of online channels, we recommend that the recycling center choose $\mathrm{S} 1$ as it must consider the stability of the entire supply chain.

(3) The increase of consumer awareness of sustainability or the reduction of online logistic costs can help increase the revenue of the recycling centers. Therefore, we recommend that recycling centers strengthen the promotion of online recycling, resource conservation, and sustainable development to consumers. We know that there are still many recycling companies that believe that sustainable development is the responsibility of the government. In addition, actively developing the logistics industry and improving the logistics level are also effective ways for the recycling center to increase revenue.

(4) Regardless of whether the recycling center chooses S1 or S3, when the city's consumer awareness of sustainability increases or the online logistics costs decrease, the city's TPR revenue will decrease. We first suggest that the TPR should observe changes in the local environment, consumer awareness, and policies in a timely manner and change the pricing strategy accordingly. In addition, we also recommend that the TPR actively cooperates with recycling centers and transforms them into sustainable enterprises. This will not only contribute to environmental protection and resource conservation, but will also help the TPR to continue its long-term business in the future.

(5) When introducing online recycling channels, we found that when the sustainable logistic costs and consumer's sustainable awareness change, it will not only affect the pricing strategy and benefits of the local TPR and recycling center, but will also affect the TPR of another city. It is very interesting to find that as the phenomenon of sustainability awareness of consumers increases, and the recycling center adopts S1, the revenue of TPR in another city will actually increase. Although in the other cases the TPR's revenue decreased or remained constant, we still suggest that it is important for the TPR not only to deal with relationships upstream and downstream between the recycling center and consumers in the supply chain, but to also observe the changes in different regional markets, as a timely response can help them to obtain more profit or escape the danger of acting too late In addition, we also advise that although many local conditions have not changed for the time being, they should also make a transition to a sustainable recycling company as soon as possible to achieve longer-term development.

\subsection{Comparison with Previous Studies}

Through the above analysis, we have made some interesting and new findings that are different from earlier studies. First of all, our research shows that regional differences have important impacts on the optimal decision making of recycling enterprises in the dual-channel reverse supply chain. However, most of the previous studies have been directed at manufacturers and retailers in the forward 
supply chain. Therefore, this study has contributed to enriching the research of the reverse supply chain. In addition, through numerical examples, we also find that when regional factors change in one region, not only will the decision of the recycling center and the local TPR be affected, but also the decision of the TPR in the other region. More specifically, when a region's consumer awareness of sustainability increases or the cost of online logistics decreases, the profit of the recycling center will continue to rise. Interestingly, the income of the TPR in this area does not always decrease as these two factors change, but in some cases it will continue to increase or have a stable fluctuation depending on the decision of the recycling center. However, in previous related studies, changes in corporate earnings tend to follow the same trend. Our research not only focuses on the new regional differences of consumers' sustainability awareness and online recycling logistics costs, but also explores the different influence patterns from the forward supply chain on pricing decisions. What is even more surprising to us is that the impact of the two factors on the income of TPR of another city is also irregular. We also obtain the adjustment plan for the pricing strategies of the recycling center and two TPRs under different circumstances. More specifically, the TPR needs to raise the recycling price when its region's consumer awareness increases, and the recycling center and another TPR need to reduce the recycling price. When the region's logistics cost is reduced, the recycling center and two TPRs all need to raise the recycling price. Therefore, compared to the relevant conclusions in the past related forward supply chain and the traditional reverse supply chain, the decision strategy and the change trend of the recycling enterprises' revenue in our study are completely different because of the different research framework in the dual-channel reverse supply chain. Furthermore, our study can also improve the management of recycling enterprises.

\subsection{Future Directions}

We now discuss the limitations of this study and the direction to be extended in future research. First of all, we assumed that the number function of used products was linear. Although most of the related articles used a linear function to describe this, it is still not accurate enough to describe its change rule. In particular, many examples listed in our research were WEEE, that is, products of a short life cycle, whose change function is particularly difficult to predict. In addition, in this paper, we only studied the problem in the framework of a reverse supply chain; in future, if the Internet can also be applied to the field of remanufacturing, then the research can be extended to the closed-loop supply chain. Finally, in addition to the logistics costs and the consumer's sustainable awareness, there are other factors such as the cost of human resources, rules and regulations that can affect pricing strategy. In future, scholars can pursue further studies in this direction.

Author Contributions: All authors contributed extensively to the work presented in this article. The research was designed and undertaken by D.W. Analysis and collection of data were performed by P.L., J.C. wrote the paper. All authors read and approved the final manuscript.

Funding: This research was funded by the National Natural Science Foundation of China [grant number 71401133], National Science Basic Research Plan in Shaanxi Province of China [grant number 2015JQ7280] and the Humanities and Social Sciences Foundation of Ministry of Education Program [grant number 16YJC630170].

Acknowledgments: This work was supported by the National Natural Science Foundation of China under Grant No. 71401133, National Science Basic Research Plan in Shaanxi Province of China under Grant No. 2015JQ7280, and the Humanities and Social Sciences Foundation of Ministry of Education Program under Grant No. 16YJC630170.

Conflicts of Interest: The authors declare no conflict of interest.

\section{Appendix}

Proof of Property 1. First, in order to solve the first order partial derivatives of $\prod_{i}$ to $p_{i}$, we can get:

$$
\partial \prod_{i} / \partial p_{i}=-2 \beta_{i} p_{i}+w \beta_{i}-\alpha_{i}
$$


Then, to solve the second order partial derivatives of $\prod_{i}$ to $p_{i}$, we can get $\partial^{2} \prod_{i} / \partial p_{i}{ }^{2}=-2 \beta_{i}$; due to $\beta_{i} \succ 0$, therefore $\partial^{2} \prod_{i} / \partial p_{i}{ }^{2} \prec 0$;

So the objective function $\prod_{i}$ is always concave with $p_{i}$. This ends the proof.

Proof of Property 2. First to solve the first order partial derivatives of $\prod_{m}$ to $w$, we can get:

$$
\partial \prod_{m} / \partial w=\frac{p_{0} \beta_{1}}{2}+\frac{p_{0} \beta_{2}}{2}-\left(\alpha_{1}+\alpha_{2}\right)-\left(\frac{2 w \beta_{1}-\alpha_{1}}{2}+\frac{2 w \beta_{2}-\alpha_{2}}{2}\right)
$$

Then, to solve the second order partial derivatives of $\prod_{m}$ to $w$, we can get:

$$
\partial^{2} \prod_{m} / \partial w^{2}=-\left(\beta_{1}+\beta_{2}\right) \prec 0 ;
$$

So the objective function $\prod_{m}$ is always concave with $w$. This ends the proof.

Proof of Property 3. First to solve the first order partial derivatives of $\prod_{m}$ to $w_{i}$, we can get:

$$
\partial \prod_{m} / \partial w_{i}=\frac{p_{0} \beta_{i}}{2}-\alpha_{i}-\left(\frac{2 w \beta_{i}-\alpha_{i}}{2}\right) ;
$$

Then, to solve the second order partial derivatives of $\prod_{m}$ to $w$, we can get:

$$
\partial^{2} \prod_{m} / \partial w_{i}^{2}=-\beta_{i} \prec 0 ;
$$

So the objective function $\prod_{m}$ is always concave with $w_{i}$. This ends the proof.

Proof of Property 4. We assume that the benefits of the differential pricing for the recycling center are:

$$
\operatorname{Max} \prod_{D}=\frac{\left[p_{0}\left(\beta_{1}+\beta_{2}\right)+\left(\alpha_{1}+\alpha_{2}\right)\right]^{2}}{8\left(\beta_{1}+\beta_{2}\right)}
$$

Assuming that the benefits of the unified pricing strategy adopted by the recycling center are:

$$
\begin{gathered}
\operatorname{Max} \prod_{U}=\sum_{i=1}^{2} \frac{\left(\alpha_{i}+p_{0} \beta_{i}\right)^{2}}{8 \beta_{i}} ; \\
\Delta=\operatorname{Max} \prod_{D}-\operatorname{Max} \prod_{U} \\
=\sum_{i=1}^{2} \frac{\left(\alpha_{i}+p_{0} \beta_{i}\right)^{2}}{8 \beta_{i}}-\frac{\left[p_{0}\left(\beta_{1}+\beta_{2}\right)+\left(\alpha_{1}+\alpha_{2}\right)\right]^{2}}{8\left(\beta_{1}+\beta_{2}\right)}=\left(\alpha_{1} \beta_{2}-\alpha_{2} \beta_{1}\right)^{2} \geq 0
\end{gathered}
$$

Therefore, for the recycling center, the benefits brought by the differential pricing strategy are always higher than the unified pricing strategy. This ends the proof.

Proof of Property 5. First to solve the first order partial derivatives of $\prod_{i}$ to $p_{i}$, we can get:

$$
\partial \prod_{i} / \partial p_{i}=-2 \beta_{i} p_{i}+w_{i} \beta_{i}-\left(1-\theta_{i}\right) \alpha_{i}+\gamma_{i} p_{e}
$$

And then to solve the second partial derivatives of $\prod_{i}$ to $p_{i}$, we can get $\partial^{2} \prod_{i} / \partial p_{i}{ }^{2}=-2 \beta_{i}$; due to $\beta_{i} \succ 0$, we can get $\partial^{2} \prod_{i} / \partial p_{i}{ }^{2} \prec 0$.

Therefore, the objective function $\prod_{i}$ is always concave with $p i$. This ends the proof. 
Proof of Property 6. First, to solve the first order partial derivatives of $\prod_{m}$ to $p_{e}$, we can get:

$$
\partial \prod_{m} / \partial p_{e}=\sum_{i=1}^{2}\left[p_{0} \beta_{i}-\alpha_{i} \theta_{i}-2 \beta_{i} p_{e}-\frac{p_{0} \gamma_{i}^{2}}{2 \beta_{i}}-\frac{\left(1-\theta_{i}\right) \alpha_{i} \gamma_{i}}{2 \beta_{i}}+\frac{c_{i} \gamma_{i}^{2}}{2 \beta_{i}}+\frac{p_{e} \gamma_{i}^{2}}{\beta_{i}}-\frac{p_{0} \gamma_{i}}{2}-\beta_{i} c_{i}+w_{i} \gamma_{i}\right]
$$

Then, to solve the second partial derivatives of $\prod_{m}$ to $p_{e}$, we can get:

$$
\partial^{2} \prod_{m} / \partial p_{e}^{2}=\sum_{i=1}^{2}\left(-2 \beta_{i}+\frac{\gamma_{i}^{2}}{\beta_{i}}\right)=\sum_{i=1}^{2}\left(\frac{\gamma_{i}^{2}-2 \beta_{i}^{2}}{\beta_{i}}\right) ;
$$

As we always assume $\left(\beta_{i} \succ \gamma_{i} \succ 0\right)$, then $\partial^{2} \prod_{m} / \partial p_{e}^{2} \prec 0$. Therefore, the objective function $\prod_{m}$ is always concave with $p_{e}$. This ends the proof.

Proof of Property 7. Through verification, due to:

$$
\begin{aligned}
& \partial \prod_{m} / \partial p_{T}=\sum_{i=1}^{2}\left(\begin{array}{c}
p_{0} \beta_{i}+2 \gamma_{i} p_{T}-2 \beta_{i} p_{T}-\beta_{i} c_{i}-p_{0} \gamma_{i}-\alpha_{i}-\frac{p_{0} \gamma_{i}\left(\beta_{i}+\gamma_{i}\right)}{2 \beta_{i}}+\frac{c_{i} \gamma_{i}\left(\beta_{i}+\gamma_{i}\right)}{2 \beta_{i}} \\
+\frac{2 p_{T} \gamma_{i}\left(\beta_{i}+\gamma_{i}\right)-\alpha_{i} \gamma_{i}\left(1-\theta_{i}\right)}{2 \beta_{i}}-\frac{2 p_{T}\left(\beta_{i}+\gamma_{i}\right)-\alpha_{i}\left(1-\theta_{i}\right)}{2}+\frac{p_{0}\left(\beta_{i}+\gamma_{i}\right)}{2}
\end{array}\right) \\
& \partial^{2} \prod_{m} / \partial p_{T}^{2}=\sum_{i=1}^{2}\left(\begin{array}{c}
2 \gamma_{i}-2 \beta_{i}+\frac{2 \gamma_{i}\left(\beta_{i}+\gamma_{i}\right)}{2 \beta_{i}}-\frac{2\left(\beta_{i}+\gamma_{i}\right)}{2} \\
=2\left(\gamma_{i}-\beta_{i}\right)+\frac{2\left(\gamma_{i}-\beta_{i}\right)\left(\beta_{i}+\gamma_{i}\right)}{2 \beta_{i}}
\end{array}\right) \prec 0
\end{aligned}
$$

function $\prod_{m}$ is always concave with $p_{T}$. This ends the proof.

Proof of Property 8. The first order partial derivatives of $\prod_{m}$ to $w_{1}$ is:

$$
\partial \prod_{m} / \partial w_{1}=\frac{c_{1} \gamma_{1}+p_{0} \beta_{1}+p_{e} \gamma_{1}-\alpha_{1}\left(1-\theta_{1}\right)}{2}-w_{1} \beta_{1}
$$

The first order partial derivatives of $\prod_{m}$ to $w_{1}$ is $\partial^{2} \prod_{i} / \partial w_{1}^{2}=-\beta_{1}$;

Similarly, the first and second derivative of $\prod_{m}$ to $w_{2}$ can be obtained:

$$
\partial \prod_{m} / \partial w_{2}=\frac{c_{2} \gamma_{2}+p_{0} \beta_{2}+p_{e} \gamma_{2}-\alpha_{2}\left(1-\theta_{2}\right)}{2}-w_{2} \beta_{2}, \partial^{2} \prod_{i} / \partial w_{2}^{2}=-\beta_{2}
$$

The first derivative of $\prod_{m}$ to $p_{e}$ :

$$
\partial \prod_{i} / \partial p_{e}=\sum_{i=1}^{2}\left(\begin{array}{c}
p_{0} \beta_{i}-\alpha_{i} \theta_{i}-2 \beta_{i} p_{e}-\beta_{i} c_{i}+w_{i} \gamma_{i}-\frac{p_{0} \gamma_{i}^{2}}{2 \beta_{i}} \\
+\frac{p_{e} \gamma_{i}^{2}}{\beta_{i}}-\frac{\alpha_{i} \gamma_{i}\left(1-\theta_{i}\right)}{2 \beta_{i}}+\frac{c_{i} \gamma_{i}^{2}}{2 \beta_{i}}-\frac{p_{0} \gamma_{i}}{2}
\end{array}\right)
$$

The second derivative: $\partial^{2} \prod_{i} / \partial p_{e}{ }^{2}=\sum_{i=1}^{2}\left(\frac{\gamma_{i}^{2}-2 \beta_{i}^{2}}{\beta_{i}}\right)$

Accordingly, we can get the Hessian matrix of $\prod_{m}$ :

$$
H\left(\prod\right)=\left[\begin{array}{ccc}
\partial^{2} \prod_{i} / \partial p_{e}{ }^{2} & \partial^{2} \prod_{i} / \partial p_{e} \partial w_{1} & \partial^{2} \prod_{i} / \partial p_{e} \partial w_{2} \\
\partial^{2} \prod_{i} / \partial w_{1} \partial p_{e} & \partial^{2} \prod_{i} / \partial w_{1}{ }^{2} & \partial^{2} \prod_{i} / \partial w_{1} \partial w_{2} \\
\partial^{2} \prod_{i} / \partial w_{2} \partial p_{e} & \partial^{2} \prod_{i} / \partial w_{2} \partial w_{1} & \partial^{2} \prod_{i} / \partial w_{2}{ }^{2}
\end{array}\right]=\left[\begin{array}{ccc}
\sum_{i=1}^{2}\left(\frac{\gamma_{i}^{2}-2 \beta_{i}{ }^{2}}{\beta_{i}}\right) & \gamma_{1} & \gamma_{2} \\
\frac{\gamma_{1}}{2} & -\beta_{1} & 0 \\
\frac{\gamma_{2}}{2} & 0 & -\beta_{2}
\end{array}\right]
$$

The first order principal minor of the Hessian matrix $\mathrm{H}(\Pi): \sum_{i=1}^{2}\left(\frac{\gamma_{i}{ }^{2}-2 \beta_{i}{ }^{2}}{\beta_{i}}\right) \prec 0$; 
The second order principal minor:

$$
\mid \sum_{i=1}^{2}\left(\begin{array}{cc}
\left.\frac{\gamma_{i}^{2}-2 \beta_{i}^{2}}{\beta_{i}}\right) & \gamma_{1} \\
\frac{\gamma_{1}}{2} & -\beta_{1}
\end{array} \mid \succ 0\right.
$$

The third order principal minor: $\left[\begin{array}{ccc}\sum_{i=1}^{2}\left(\frac{\gamma_{i}^{2}-2 \beta_{i}{ }^{2}}{\beta_{i}}\right) & \gamma_{1} & \gamma_{2} \\ \frac{\gamma_{1}}{2} & -\beta_{1} & 0 \\ \frac{\gamma_{2}}{2} & 0 & -\beta_{2}\end{array}\right] \prec 0$.

According to the above, we reach the conclusion that $\mathrm{H}(\Pi)$ is a negative definite matrix. So the objective function $\prod_{m}\left(p_{e}, w_{1}, w_{2}\right)$ is always concave. This ends the proof.

\section{References}

1. Sun, M.; Yang, X.; Huisingh, D. Consumer behavior and perspectives concerning spent household battery collection and recycling in China: A case study. J. Clean. Prod. 2015, 107, 775-785. [CrossRef]

2. Zhang, S.; Ding, Y.; Liu, B. Challenges in legislation, recycling system and technical system of waste electrical and electronic equipment in China. Waste Manag. 2015, 45, 361-373. [CrossRef] [PubMed]

3. Toffel, M.W. The growing strategic importance of end-of-life product management. Calif. Manag. Rev. 2003, 45, 102-129. [CrossRef]

4. Kuo, T.C. The study of production and inventory policy of manufacturing/remanufacturing environment in a closed-loop supply chain. Int. J. Sustain. Eng. 2011, 4, 323-329. [CrossRef]

5. Chen, X.; Tai, C.T.; Wu, L. Business Models for Social Innovation of Municipal Solid Waste Recycling Companies: Comparison of Two Business Cases in Thailand and Taiwan. Sustainability 2018, 10, 1009. [CrossRef]

6. Electrical Appliance Recycling Technology Center. The White Paper on the 2016 WEEE of the Recycling Industry in China. Available online: http:/ / weee-epr.org/channel.php?id=1\&category_id=9 (accessed on 24 May 2017).

7. Wen, P.; Su, J.; Zhong, D. Development of an Online System for Recycling Consumer Electronic Products Using the Internet, NFC and RFID Technologies. Key Eng. Mater. 2014, 572, 90-99.

8. Banytè, J.; Brazionienè, L.; Gadeikienè, A. Investigation of green consumer profile: A case of Lithuanian market of eco-friendly food products. Econ. Manag. 2010, 15, 374.

9. Jaca, C.; Prieto-Sandoval, V.; Psomas, E.; Ormazabal, N. What should consumer organizations do to drive environmental sustainability? J. Clean. Prod. 2018, 181, 201-208. [CrossRef]

10. Balderjahn, I.; Buerke, A.; Kirchgeorg, M.; Peyer, M.; Seegebarth, B.; Wiedmann, K.-P. Consciousness for sustainable consumption: Scale development and new insights in the economic dimension of consumers' sustainability. AMS Rev. 2013, 3, 181-192. [CrossRef]

11. China Chain Store \& Franchise Association. Report on Consumer Awareness and Behavior Change in Sustainable Consumption. Available online: http://www.ccfa.org.cn/portal/cn/view.jsp?lt=33\&id=432783 (accessed on 4 December 2017).

12. You, H.; Wei, H.; Hong, Q. Distribution Mode of Urban Renewable Resources Recycling Based on the Internet. Adv. Mater. Res. 2013, 616-618, 1636-1639.

13. Li, C.; Feng, L. Strategic analysis of dual-recycling channel design for WEEE considering customer preferences. J. Syst. Eng. 2016, 31, 494-503.

14. Feng, L.; Govindan, K.; Li, C. Strategic planning: Design and coordination for dual-recycling channel reverse supply chain considering consumer behavior. Eur. J. Oper. Res. 2017, 260, 601-612. [CrossRef]

15. Giri, B.C.; Chakraborty, A.; Maiti, T. Pricing and return product collection decisions in a closed-loop supply chain with dual-channel in both forward and reverse logistics. J. Manuf. Syst. 2017, 42, 104-123. [CrossRef]

16. Yan, R.; Pei, Z. Retail services and firm profit in a dual-channel market. J. Retail. Consum. Serv. 2009, 16, 306-314. [CrossRef] 
17. Tsay, A.A.; Agrawal, N. Channel Conflict and Coordination in the E-Commerce Age. Prod. Oper. Manag. 2010, 13, 93-110. [CrossRef]

18. Xiao, T. Risk sharing and information revelation mechanism of a one-manufacturer and one-retailer supply chain facing an integrated competitor. Eur. J. Oper. Res. 2009, 196, 1076-1085. [CrossRef]

19. Yan, R.; Pei, Z. Information asymmetry, pricing strategy and firm's performance in the retailer- multi-channel manufacturer supply chain. J. Bus. Res. 2011, 64, 377-384. [CrossRef]

20. Savaskan, R.C.; Van Wassenhove, L.N. Reverse Channel Design: The Case of Competing Retailers. Manag. Sci. 2006, 52, 1-14. [CrossRef]

21. Cachon, G.P.; Lariviere, M.A. Supply Chain Coordination with Revenue-Sharing Contracts: Strengths and Limitations. Manag. Sci. 2005, 51, 30-44. [CrossRef]

22. Ferguson, M.; Guide, V.D., Jr.; Souza, G.C. Supply Chain Coordination for False Failure Returns. Manuf. Serv. Oper. Manag. 2006, 8, 376-393. [CrossRef]

23. Wongthatsanekorn, W.; Realff, M.J.; Ammons, J.C. Multi-time scale Markov decision process approach to strategic network growth of reverse supply chains. Omega 2010, 38, 20-32. [CrossRef]

24. Baker, E.; Jin, Y.; Muriel, A.; Vits, J. Impact of the quality and cost of information on the reverse supply chain. Environ. Microbiol. 2010, 9, 2495-2507.

25. Gu, Q.L.; Gao, T.G.; Shi, L.S. Price Decision Analysis for Reverse Supply Chain Based on Game Theory. Syst. Eng. Theory Pract. 2005, 3, 21-25.

26. Wang, Y.Y.; Li, B.Y.; Shen, L. The Price Decision Model for the System of Supply Chain and Reverse Supply Chain. Chin. J. Manag. Sci. 2006, 14, 40-45.

27. Savaskan, R.C.; Bhattacharya, S.; Van Wassenhove, L.N. Closed-Loop Supply Chain Models with Product Remanufacturing. Manag. Sci. 2004, 50, 239-252. [CrossRef]

28. Huang, M.; Song, M.; Lee, L.H.; Ching, W.K. Analysis for strategy of closed-loop supply chain with dual recycling channel. Int. J. Prod. Econ. 2013, 144, 510-520. [CrossRef]

29. Hong, X.; Wang, Z.; Wang, D.; Zhang, H. Decision models of closed-loop supply chain with remanufacturing under hybrid dual-channel collection. Int. J. Adv. Manuf. Technol. 2013, 68, 1851-1865. [CrossRef]

30. Big Data Research Institute of Loving Recycling. Loving Recycling Releases Big Data: Three Years of Change in the Recycling Market. Available online: http://mi.techweb.com.cn/tmt/2018-01-05/2626173.shtml (accessed on 5 January 2018).

31. National Development and Reform Commission of People's Republic of China. 2015 Circular Economy Promotion Plan. Available online: http:/ / www.gov.cn/xinwen/2015-04/20/content_2849620.htm (accessed on 14 April 2015).

32. National Development and Reform Commission of People's Republic of China. Three-year Action Plan of "Internet+" Green Ecology. Available online: http://www.gov.cn/xinwen/2016-01/21/content_5035064. htm (accessed on 11 January 2015).

33. Zhang, T.; Wang, X.; Chu, J.; Liu, X.; Cui, P. Automotive recycling information management based on the internet of things and RFID technology. In Proceedings of the IEEE International Conference on Advanced Management Science, Chengdu, China, 9-11 July 2010; Volume 2, pp. 620-622.

34. Karakayali, I.; Emir-Farinas, H.; Akcali, E. An analysis of decentralized collection and processing of end-of-life products. J. Oper. Manag. 2007, 25, 1161-1183. [CrossRef]

35. Choi, T.M.; Li, Y.; Xu, L. Channel leadership, performance and coordination in closed loop supply chains. Int. J. Prod. Econ. 2013, 146, 371-380. [CrossRef]

36. Sheng, Z.H.; Xu, F. Study on manufacturer's pricing strategy with dual-channel based on regional gap background. J. Manag. Sci. China 2010, 13, 1-10.

37. Xu, F.; Sheng, Z.; Chen, G. Study on manufacturer's channel selection and pricing strategy based on regional gap background. J. Syst. Sci. Math. Sci. 2011, 31, 1444-1453.

38. Pasternack, B.A. Optimal Pricing and Return Policies for Perishable Commodities. Mark. Sci. 2008, 27, 131-132. [CrossRef]

39. Kurata, H.; Yao, D.Q.; Liu, J.J. Pricing policies under direct vs. indirect channel competition and national vs. store brand competition. Eur. J. Oper. Res. 2007, 180, 262-281. [CrossRef]

40. Chiang, W.K.; Chhajed, D.; Hess, J.D. Direct Marketing, Indirect Profits: A Strategic Analysis of Dual-Channel Supply-Chain Design. Manag. Sci. 2003, 49, 1-20. [CrossRef] 
41. Huang, W.; Swaminathan, J.M. Introduction of a second channel: Implications for pricing and profits. Eur. J. Oper. Res. 2009, 194, 258-279. [CrossRef]

42. Hua, G.; Wang, S.; Cheng, T.E. Price and lead time decisions in dual-channel supply chains. Eur. J. Oper. Res. 2010, 205, 113-126. [CrossRef]

43. Wang, H.; Dan, R. Regional growth differences in China for 1995-2013: An empirical integrative analysis of their sources. Ann. Reg. Sci. 2018, 60,1-19. [CrossRef]

44. Buerke, A.; Straatmann, T.; Lin-Hi, N.; Müller, K. Consumer awareness and sustainability-focused value orientation as motivating factors of responsible consumer behavior. Rev. Manag. Sci. 2017, 11, 1-33. [CrossRef]

45. Zander, P.K.; Risius, A.; Feucht, Y.; Janssen, M.; Hamm, U. Sustainable aquaculture products: Implications of consumer awareness and of consumer preferences for promising market communication in Germany. J. Aquat. Food Prod. Technol. 2017, 27, 5-20. [CrossRef]

46. Okewu, E.; Misra, S.; Maskeliūnas, R.; Damaševičius, R.; Fernandez-Sanz, L. Optimizing Green Computing Awareness for Environmental Sustainability and Economic Security as a Stochastic Optimization Problem. Sustainability 2017, 9, 1857. [CrossRef]

47. Cattani, K.; Gilland, W.; Heese, H.S.; Swaminathan, J. Abstract Boiling Frogs: Pricing Strategies for a Manufacturer Adding a Direct Channel that Competes with the Traditional Channel. Prod. Oper. Manag. 2005, 15, 40-56.

48. Loving Recycling. Consult the Price of Second-Hand Iphone6. Available online: http://www.aihuishou. com/product/17461.html (accessed on 1 March 2018).

(C) 2018 by the authors. Licensee MDPI, Basel, Switzerland. This article is an open access article distributed under the terms and conditions of the Creative Commons Attribution (CC BY) license (http:/ / creativecommons.org/licenses/by/4.0/). 